BANCA D'ITALIA

E U R O S I S T E M A

Questioni di Economia e Finanza

(Occasional Papers)

Firms' leverage across business cycles

by Antonio. De Socio

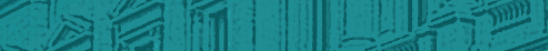



BANCA D'ITALIA

E U R O S I S T E MA

\section{Questioni di Economia e Finanza}

(Occasional Papers)

Firms' leverage across business cycles

by Antonio De Socio

Number 587 - December 2020 
The series Occasional Papers presents studies and documents on issues pertaining to the institutional tasks of the Bank of Italy and the Eurosystem. The Occasional Papers appear alongside the Working Papers series which are specifically aimed at providing original contributions to economic research.

The Occasional Papers include studies conducted within the Bank of Italy, sometimes in cooperation with the Eurosystem or other institutions. The views expressed in the studies are those of the authors and do not involve the responsibility of the institutions to which they belong.

The series is available online at www.bancaditalia.it.

ISSN $1972-6627$ (print)

ISSN 1972-6643 (online)

Printed by the Printing and Publishing Division of the Bank of Italy 


\title{
FIRMS’ LEVERAGE ACROSS BUSINESS CYCLES
}

\author{
Antonio De Socio*
}

\begin{abstract}
Based on a large sample of mostly unlisted non-financial companies, this paper studies the relationship between business cycles and firms' leverage, disentangling the relative contributions of debt and equity and assessing the role of firm size in explaining cross-sectional heterogeneity. I find that aggregate leverage initially increases during busts, as debt growth remains steady, while the counterbalancing contribution of equity is smaller; after one year, as debt slows down, leverage decreases. Moreover, firm size matters, also after controlling for other proxies of financial frictions (age, risk, profitability, debt structure): leverage increases more at the beginning of busts for both very large and smaller firms; after one year, leverage decreases less for the latter, mainly due to persistently lower profits.
\end{abstract}

JEL Classification: E32, G01, G32.

Keywords: debt, equity, firm size, business cycles, crises.

DOI: $10.32057 / 0$. QEF.2020.587

\section{Contents}

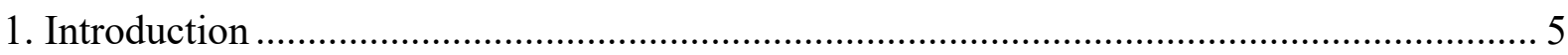

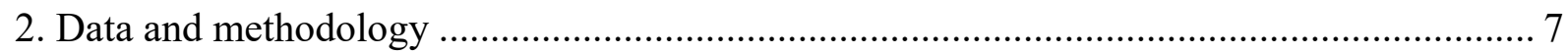

2.1 Firms accounting data and identification of the business cycles .............................. 7

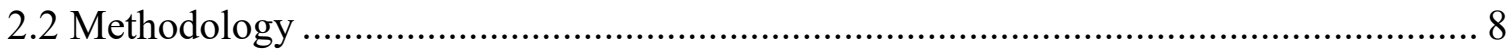

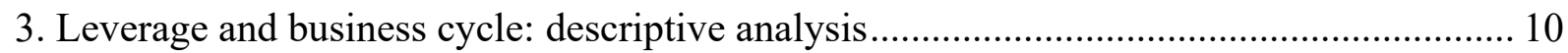

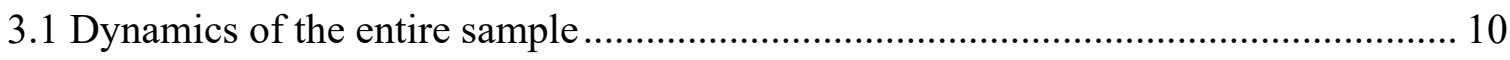

3.2 Correlations by size, age, profitability, riskiness, and debt structure ........................ 13

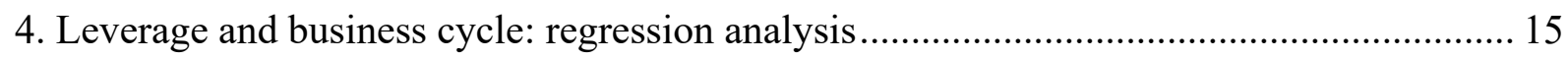

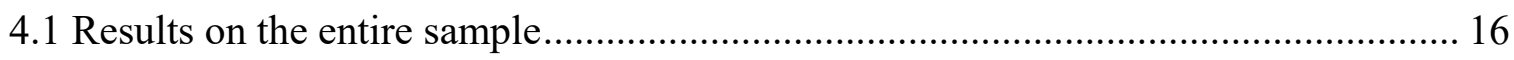

4.2 Results by groups of firms (size, age, profitability, riskiness, debt structure)............. 17

4.3 The role of size controlling for other characteristics ............................................... 18

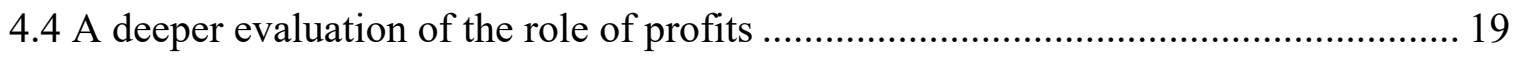

5. Discussion of main findings and future developments .................................................. 21

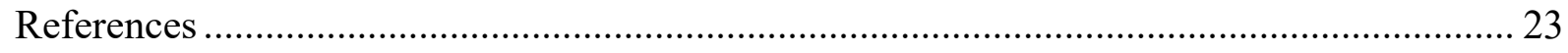

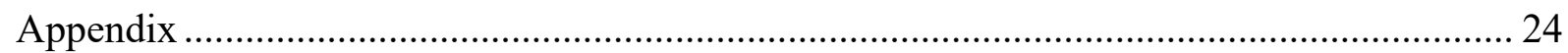

\footnotetext{
* Bank of Italy, Directorate General for Economics, Statistics and Research.
} 



\section{Introduction *}

The financial structure of firms reflects their needs of sources of funding. Access to external resources is especially important to support investments, as internal funding is usually sufficient to sustain only ordinary activity. The study of leverage dynamics is especially important during the negative phases of the cycle, as firms' financial structure, self-financing capacity, and access to external funding interact with both business activity (investments and employment) and financial stability (solvency risks for investors).

This paper aims at shedding light on the relation between business cycles and leverage of nonfinancial corporations. A consensus in the empirical corporate finance literature on this issue is lacking, also due to the heterogeneity of data used. Studies based both on macro and micro data find that debt is procyclical, while results about equity are mixed, also because aggregate results are often driven by a small number of very large firms.

Jermann and Quadrini (2012) rely on US flow of funds and find that equity (debt) financing is countercyclical (procyclical), suggesting that busts lead to a rebalancing of firms financial structure. Studies relying on micro data of listed firms that distinguish by size classes confirm that debt is procyclical, but do not agree about the cyclicality of equity. According to Covas and Den Haan (2011) equity is acyclical or countercyclical if all firms are included, while it is procyclical once very large companies (top 1 per cent) are excluded. The results depend also on the definition of equity. They prefer two measures of "net amount of equity raised" (with or without dividends) derived as the change of the book value of equity because: 1) in Compustat accumulated retained earnings are excluded, thus including only funding from shareholders; 2) other measures like the "gross sale of stock" or the "net sale of stock" (gross sale of stock minus repurchases) include also issuances related to warrants, stock options or mergers. Karabounis, Macnamara, and McCord (2014) and Begenau and Salomao (2018) find instead that procyclicality of equity is limited to smaller size classes (excluding the top 25 instead of the top 1 per cent). In particular, Begenau and Salomao (2018) rely on "shareholders' equity net of retained earnings" to include only external funding and claim that Covas and Den Haan (2011) incorrectly state that book value of equity excludes accumulated retained earnings; in turn, this refinement explains the different findings on low cyclicality of equity and size. Moreover, they also find that equity is procyclical (anticyclical) for smaller less profitable (larger more profitable) companies, suggesting that dimension does not capture all heterogeneity

The contribution to the literature relies on the use of individual data of 165,000 Italian firms between 1982 and 2018. Since nearly all of them are unlisted, the results of this study are more general than previous analyses limited to public companies. The availability of data on smaller firms provides not only wider heterogeneity of firms' characteristics, but also information on firms that are more likely to experience financial frictions during downturns.

Unlike previous works that analyse separately changes of debt and of equity, this paper studies them jointly deriving a decomposition of the change of leverage in these two components. ${ }^{1}$ As debt

\footnotetext{
* I wish to thank Alessio Ciarlone, Davide Fantino, Andrea Nobili, Paolo Piselli, Andrea Silvestrini and Giordano Zevi for their suggestions and the participants to internal seminars at the Bank of Italy for their helpful comments. The views expressed in this paper are those of the author and do not necessarily reflect those of the Bank of Italy.

${ }^{1}$ The analysis is based on the change of leverage because it is less affected by the econometric issues of estimations based on the level of leverage. As discussed in Murray and Shen (2019), estimation of the time variation of the level of leverage should take into account the speed of adjustment towards a target level that is possibly time-varying or even a theoretical value beyond the scope of firm managers.
} 
and equity usually drive leverage in opposite directions, their combined effect could be ambiguous, especially during busts: leverage could increase because debt grows faster than equity or because a decrease of debt is offset by a larger decline of equity due to losses. In this respect, this study also assess the role of profits, a key driver of equity. Moreover, firm heterogeneity is not restricted to size (as in the existing literature), but takes into account also age, profitability, riskiness, and debt structure. Indeed these characteristics are important for leverage dynamics, particularly for unlisted firms ${ }^{2}$ and during slumps, as they proxy heterogeneous exposure to financial frictions.

The main finding of the previous literature, i.e. that the aggregate dynamics of leverage depends on a minority of very large firms, is confirmed. During the long booms preceding the 1992-93 and 2001-03 downturns, leverage increased more persistently compared to the shorter expansion before the global financial crisis. The contemporaneous correlation between busts and leverage is positive, while the lagged one is negative. The decomposition developed in the paper explains the second finding: as both debt and equity are procyclical, they drive the financial structure in opposite directions and their combined effects depend on the different behaviours during busts. Leverage goes initially up because debt growth remains somehow steady, while the counterbalancing effect of equity becomes smaller; after one year leverage decreases, as debt slows down. Importantly, the dynamics of equity during busts depends on procyclical profits, which dwarfs the contribution of shareholders' funds or distributed dividends.

A novel result is that leverage dynamics differ across size classes, and this finding persists also when including other firms' characteristics. ${ }^{3}$ The initial increase of leverage during busts is more pronounced for both smaller (I-III decile by assets) and very large companies (X decile by assets) compared to mid-size firms. The underlying forces are however different: smaller firms are more affected by the negative effects of business cycles on equity caused by lower profits or even losses; the largest have lower financial frictions and their debt slowdown is more subdued. These results also imply that for the majority of firms (mid-size, IV-IX deciles) the relative contributions of debt and equity imply a more balanced leverage dynamics. One year after the busts begin, smaller firms tend to improve less their financial structure, mainly due to persistent low or negative profits, suggesting that their problems are not short-lived.

Overall, the results provide a guidance to assess which companies benefit more from policy measures aimed at rebalancing financial structures during crises, an issue that has become more important due to the effects of the Covid-19 pandemic.

The paper is structured as follows. Section 2 summarises data on firm-level variables and business cycles in Italy and describes the methodological features of the analysis. Sections 3 and 4 show the results of correlation and regression analyses, respectively. Section 5 summarises the main findings, discusses their relevance for the current pandemic crisis, and presents possible future developments.

\footnotetext{
${ }^{2}$ Dinlersoz et al. (2018) report extensive heterogeneity in leverage by firm age and size, especially that small (young) unlisted firms are the least (more) leveraged. Frank and Goyal (2009) find that profitability is an important driver of equity, especially for smaller firms. Farre-Mensa and Ljungqvist (2016) evaluate different measures of financial constraints, finding they are more relevant for private companies; I include riskiness, the share of short-term or bank debt to proxy respectively for the probability of bankruptcy, the refinancing risk and the exposure to lenders' problems.

${ }^{3}$ The importance of size during business cycles shares some similarities with Crouzet and Mehrotra (2018), who analyse the cyclicality of sales growth by size classes of a sample of mostly unlisted US manufacturing firms finding that dimension matters also controlling for proxies of financial strength (leverage, liquidity, bank-dependence).
} 


\section{Data and methodology}

\subsection{Firms accounting data and identification of the business cycles}

This paper combines detailed firm-level data of around 165.000 Italian non-financial corporations and information on business cycles starting from 1982, a time span that encompasses two severe downturns: the European monetary system crisis in the early Nineties and the more recent global financial and euro area sovereign debt crises.

The source of firms accounting data is Centrale dei Bilanci $(\mathrm{CeBi})$, the only provider of yearly balance sheet information whose database covers the two main crises. Its data refer to limited liability companies and include nearly all the medium and large firms and around half of the small ones (see Appendix A1 for further details). A more comprehensive database of the Italian corporate sector that includes also micro firms is Cerved, whose data are however available only from 1993 and therefore cannot be used to properly analyse the crisis in the early Nineties.

$\mathrm{CeBi}$ data are used to derive the main variable of interest, leverage, calculated as the ratio between financial debt (bonds, bank loans and other loans, also from shareholders) and its sum with equity at book value. The main analyses of the paper focus on the yearly change of leverage in a 2-year closed sample, subtracting from equity the value of reserves due to asset revaluations. This choice tackles three issues discussed in Appendix A2 (the accounting effect of revaluations of assets on the value of equity, the influence of firms' demography and the impact of inflation).

Differently from previous works that focus separately on changes of debt and equity, I disentangle their relative contribution to financial structure over time. As discussed more in detail in Appendix A2, the change of leverage is decomposed into the sums of debt and equity as follows:

(a) contribution of debt $=\frac{\mathrm{E}_{t} * \Delta \mathrm{D}_{t}}{\left(\mathrm{D}_{t}+E_{t}\right) *\left(\mathrm{D}_{t-1}+E_{t-1}\right)}$

$$
\text { contribution of equity }=-\frac{\mathrm{D}_{t} * \Delta \mathrm{E}_{t}}{\left(\mathrm{D}_{t}+E_{t}\right) *\left(\mathrm{D}_{t-1}+E_{t-1}\right)}
$$

in order to precisely quantify how much the dynamic of leverage is due to the changes of debt, $\Delta \mathrm{D}_{t}$, and of equity, $\Delta \mathrm{E}_{t}$. This information is important as they drive leverage in opposite directions (positive and negative, respectively) and their combined effect is therefore ambiguous.

I also include in the analysis a specific assessment of equity, with the main aim of evaluating the relevance of self-financing (profits net of distributed dividends) compared to external funding (shareholders' funds). As equity (E) is the sum of shareholders' funds (SF), reserves (RES), profits (PR) minus dividends (DIV), the percentage change of equity between $t$ and $t+1$ is the following:

(c) $\quad \frac{\Delta \mathrm{E}_{t}}{E_{t-1}}=\frac{\Delta \mathrm{SF}_{t}}{E_{t-1}}+\frac{\Delta \mathrm{RES}_{t}}{E_{t-1}}+\frac{P R_{t}}{E_{t-1}}-\frac{\mathrm{DIV}_{t}}{E_{t-1}}$

The other firm characteristics derived from $\mathrm{CeBi}$ and employed in this paper to evaluate the heterogeneity of the relation between leverage and business cycles are the following: size (based on total assets), age, profitability (equal to the ratio EBITDA/assets), riskiness (based on Cerved Score 4), and the shares of bank or short term financial debt.

The source of information on the Italian business cycles, in particular with respect to the identification of booms (trough to peak) and busts (peak to trough), are Istat (2011) and Bank of Italy (2018). Similarly to the classification of the National Bureau of Economic Research (NBER) for the 
US, the two phases of the cycle are based on a composite indicator relying on monthly and quarterly data and therefore some years can include both.

I cope with the different time frequency of macroeconomic information and firm-level data as follows (additional information are presented in Appendix A3). Busts are identified from the official classification if a specific year includes at least three quarters going from peak to trough, which happens in most cases $(1992,1993,1996,2001,2002,2008,2012)$. Four years $(2003,2009,2011$, 2013) are ambiguous, as they include two quarters of booms and busts; all of them are classified as contractionary based on quarterly GDP growth rates.

The time span under analysis can be divided as follows: after a 3-year long bust (1980-1982), between 1983 and 2018 there have been 11 contractionary years (1992-93, 1996, 2001-3, 2008-09 and 2011-13) and 25 expansionary years. Based on this division, a dummy equal to one during the latter is used as the key variable to analyse the relationship between leverage and the two phases of the business cycle. A quantitative definition, based on yearly averages of quarterly GDP growth rates, is also used as an alternative to assess the main descriptive results found with the dummy variable.

\subsection{Methodology}

In order to assess the relations between business cycles and leverage, this study relies on two complementary approaches: the first one uses graphical analyses and correlations, and the second is based on a regression analysis. While both evaluate the role of firms size and other characteristics (age, profitability, riskiness, debt structure), the second innovates compared to the extant literature as it specifically tests if size continues to matter controlling for other possible confounding factors.

In both approaches, two dummy variables are created in order to identify both the contemporaneous and the lagged relation between business cycles and leverage: i) "BUST", which is equal to one during slumps (1992-93, 1996, 2001-03, 2008-09, 2011-13); ii) "BUST+1Y", which is the same dummy shifted one year ahead.

The first approach links the different phases of a business cycle with three variables, the change of leverage $\left(\Delta L e v_{G t}\right)$ and its two components (i.e. the contribution of debt and equity to the variation of leverage), according to the following equation

(d) $\Delta L e v_{G t}=\frac{\mathrm{E}_{G t} * \Delta \mathrm{D}_{G t}}{\left(\mathrm{D}_{G t}+E_{G t}\right) *\left(\mathrm{D}_{G t-1}+E_{G t-1}\right)}-\frac{\mathrm{D}_{G t} * \Delta \mathrm{E}_{G t}}{\left(\mathrm{D}_{G t}+E_{G t}\right) *\left(\mathrm{D}_{G t-1}+E_{G t-1}\right)}$

where debt and equity are summed across all the firms belonging to a specific group level " $\mathrm{G}_{\mathrm{t}}$ ", which in turn is based upon specific firm characteristics.

More precisely, 22 different groups have been defined each year according to:

- $\quad$ size: 10 deciles (based on assets distribution);

- age: 3 classes (young: first quartile by age; median: second and third quartile; old: last quartile);

- profitability: 2 classes (based on a dummy=1 if EBITDA is positive);

- riskiness: 3 classes (based on Cerved Z-score);

- debt duration: 2 classes (using a dummy=1 if the share of short-term debt is equal to 1 );

- reliance on bank debt: 2 classes (using a dummy=1 if the share of bank debt is equal to 1 ). 
The second approach relies upon three sets of panel regressions with firm fixed effects and firmclustered standard errors; each set includes six regressions that combine three dependent variables and two cycle-related dummies. The three dependent variables, all winsorized each year at the $1^{\text {st }}$ and $99^{\text {th }}$ percentile, are the change of leverage $\left(\mathrm{DLEV}_{\mathrm{it}}\right)$, the contribution of debt $\left(\mathrm{DF}_{\mathrm{it}}\right)$ and that of equity (EQ $\mathrm{E}_{\mathrm{it}}$. A first specification includes the dummy BUST and a second one the dummy BUST $+1 \mathrm{Y}$. The coefficients of these two dummies measure, for each dependent variable, the difference of its mean between slumps (or one year later) and the remaining reference years.

First set of regressions: include the entire sample of firms as follows

(1) $\mathrm{DLEV}_{\mathrm{it}}=\mathrm{a}_{\mathrm{i} 1}+\beta_{1} \mathrm{BUST}+\mathrm{e}_{1 \mathrm{it}}$

(2) $\mathrm{DF}_{\mathrm{it}}=\mathrm{a}_{\mathrm{i} 2}+\beta_{2} \mathrm{BUST}+\mathrm{e}_{2 \mathrm{it}}$

(3) $\mathrm{EQ}_{\mathrm{it}}=\mathrm{a}_{\mathrm{i} 3}+\beta_{3} \mathrm{BUST}+\mathrm{e}_{3 \mathrm{it}}$

(4) $\mathrm{DLEV}_{\mathrm{it}}=\mathrm{a}_{\mathrm{i} 4}+\beta_{4} \mathrm{BUST}_{+1 \mathrm{Y}}+\mathrm{e}_{4 \mathrm{it}}$

(5) $\mathrm{DF}_{\mathrm{it}}=\mathrm{a}_{\mathrm{i} 5}+\beta_{5} \mathrm{BUST}_{+1 \mathrm{Y}}+\mathrm{e}_{5 \mathrm{it}}$

(6) $\mathrm{EQ}_{\mathrm{it}}=\mathrm{a}_{\mathrm{i} 6}+\beta_{6} \mathrm{BUST}_{+1 \mathrm{Y}}+\mathrm{e}_{6 \mathrm{it}}$

Since algebraically the change of leverage is the sum of the contributions of debt and equity, the role of the two components can be disentangled, both during slumps (BUST) and with a lag

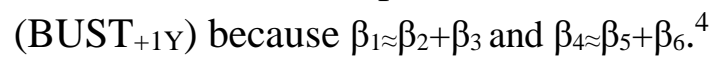

Second set of regressions: based on regressions (1-6) for each of the 22 groups. Its aim is to evaluate the existence of firms heterogeneity upon the phenomenon at stake, i.e. whether the change of leverage and the relative contribution of debt and equity during slumps differ according to these firm characteristics.

Third set of regressions: extends the previous one, by taking contemporaneously into account all firm characteristics. I run regressions (1-6) including again the entire sample (instead of firms belonging to a specific group separately) and interacting first each size decile with busts or with a lag (see A1 and A2) and then both size deciles and all other variables with busts or with a lag (see B1 and B2). More specifically the specifications are the following:

(A1) $\mathrm{Y}_{\mathrm{it}}=\mathrm{a}_{S} \mathrm{I}(\mathrm{SIZE})_{\mathrm{it}}+\boldsymbol{\beta} \mathrm{sI}(\mathrm{SIZE})_{\mathrm{it}}{ }^{*} \mathrm{BUST}+\mathrm{e}_{\mathrm{it}}$

(A2) $\mathrm{Y}_{\mathrm{it}}=\mathrm{a}_{\mathrm{S}} \mathrm{I}(\mathrm{SIZE})_{\mathrm{it}}+\boldsymbol{\beta} \mathrm{sI}(\mathrm{SIZE})_{\mathrm{it}} * \mathrm{BUST}_{+1 \mathrm{Y}}+\mathrm{e}_{\mathrm{it}}$

(B1) $\mathrm{Y}_{\mathrm{it}}=\mathrm{a}_{\mathrm{S}} \mathrm{I}(\mathrm{SIZE})_{\mathrm{it}}+\boldsymbol{\beta} \mathrm{sI}(\mathrm{SIZE})_{\mathrm{it}} * \mathrm{BUST}+\mathrm{a}_{\mathrm{D}} \mathrm{I}(\mathrm{DUMMIES})_{\mathrm{it}}+\beta_{\mathrm{D}} \mathrm{I}(\mathrm{DUMMIES})_{\mathrm{it}} * \mathrm{BUST}+\mathrm{e}_{\mathrm{it}}$

(B2) $\mathrm{Y}_{\mathrm{it}}=\mathrm{asI}_{\mathrm{S}}(\mathrm{SIZE})_{\mathrm{it}}+\boldsymbol{\beta} \mathrm{sI}(\mathrm{SIZE})_{\mathrm{it}} * \mathrm{BUST}_{+1 \mathrm{Y}}+\mathrm{a}_{\mathrm{D}} \mathrm{I}(\mathrm{DUMMIES})_{\mathrm{it}}+\beta_{\mathrm{D}} \mathrm{I}(\mathrm{DUMMIES})_{\mathrm{it}} * \mathrm{BUST}_{+1 \mathrm{Y}}+\mathrm{e}_{\mathrm{it}}$

where

$\mathrm{Y}_{\mathrm{it}}=\mathrm{DLEV}_{\mathrm{it}}$ or $\mathrm{DF}_{\mathrm{it}}$ or $\mathrm{EQ}_{\mathrm{it}}$ (as in equations $1-4$ or 2-5 or 3-6)

I(SIZE) are 10 dummies, one for each size decile

I(DUMMIES) are 7 dummies ( 2 for age classes, 2 for risk classes, 1 for profitability, share of bank or short-term debt)

${ }^{4}$ The equalities $\beta 1=\beta 2+\beta 3$ and $\beta 4=\beta 5+\beta 6$ do not hold because the winsorization considers the distribution of each dependent variable separately. 
The coefficients of interest are the $\beta_{\mathrm{S}}$, which represent, for each size class, the average change of leverage (or the contribution of debt and equity) during a slump (A1 and A2) or one year later (B1 and B2) compared with the remaining reference years. While specifications A1 and A2 are similar to those presented in the second set of regressions, specifications B1 and B2 are the main object of interest of the analysis as all other firm characteristics are controlled for.

Regressions on equity components: I conclude the regression analysis with a specific assessment of equity, replicating the first set of regressions and the third one (limiting to A1 and B1) as follows:

$\left(1^{\mathrm{e}}-5^{\mathrm{e}}\right) \quad \mathrm{Y}_{\mathrm{it}}=\mathrm{a}_{\mathrm{i}}+\beta_{\mathrm{YBUST}}+\mathrm{e}_{\mathrm{it}}$

$\left(6^{\mathrm{e}}-10^{\mathrm{e}}\right) \quad \mathrm{Y}_{\mathrm{it}}=\mathrm{a}_{\mathrm{i}}+\beta_{\mathrm{YBUST}}+1 \mathrm{Y}+\mathrm{e}_{\mathrm{it}}$

$\left(\mathrm{A} 1^{\mathrm{e}}\right) \quad \mathrm{Y}_{\mathrm{it}}=\mathrm{as}_{\mathrm{S}} \mathrm{I}(\mathrm{SIZE})_{\mathrm{it}}+\boldsymbol{\beta} \mathrm{sI}(\mathrm{SIZE})_{\mathrm{it}} * \mathrm{BUST}+\mathrm{e}_{\mathrm{it}}$

$\left(B 1^{\mathrm{e}}\right) \quad \mathrm{Y}_{\mathrm{it}}=\mathrm{aSI}_{\mathrm{SI}}(\mathrm{SIZE})_{\mathrm{it}}+\boldsymbol{\beta} \mathrm{sI}(\mathrm{SIZE})_{\mathrm{it}} * \mathrm{BUST}+\mathrm{a}_{\mathrm{D}} \mathrm{I}(\mathrm{DUMMIES})_{\mathrm{it}}+\beta_{\mathrm{D}} \mathrm{I}(\mathrm{DUMMIES})_{\mathrm{it}} * \mathrm{BUST}+\mathrm{e}_{\mathrm{it}}$

where the five dependent variables $\mathrm{Y}$ are the equity growth rate $\left(1^{\mathrm{e}}\right.$ and $\left.6^{\mathrm{e}}\right)$ and its four components: i) shareholders' funds $\left(2^{\mathrm{e}}\right.$ and $\left.7^{\mathrm{e}}\right)$; ii) reserves $\left(3^{\mathrm{e}}\right.$ and $\left.8^{\mathrm{e}}\right)$; iii) profits $\left(4^{\mathrm{e}}\right.$ and $\left.9^{\mathrm{e}}\right)$; and iv) dividends $\left(5^{\mathrm{e}}\right.$ and $\left.10^{\mathrm{e}}\right)$. By construction, the estimated value $\beta_{\mathrm{Y}}$ in equations $1^{\mathrm{e}}$ and $6^{\mathrm{e}}$ are nearly equal to the sum of the values of $\left(2^{\mathrm{e}}\right.$ to $\left.5^{\mathrm{e}}\right)$ and $\left(7^{\mathrm{e}}\right.$ to $\left.10^{\mathrm{e}}\right)$, respectively.

\section{Leverage and business cycle: descriptive analysis}

\subsection{Dynamics of the entire sample}

Figure 1 shows the time series between 1983 and 2018 of the three variables of interest: the change of leverage, and the contributions of debt and equity; contractionary years are shown in blue and red for debt and equity, respectively.

This evidence shows some differences in leverage dynamics during the two phases of business cycles. During slumps, the contemporaneous and lagged relations between economic activity and firms' financial structure are reversed: leverage typically goes up in the first year of busts (1992, 2001, 2008, 2011) while it decreases immediately afterwards (except for 1993). The different role of debt and equity explains leverage dynamics during slumps. In the first year of a bust the increase of leverage is driven by a somehow steady growth of debt that overwhelms the smaller counterbalancing contribution of equity; instead, after one year leverage decreases as debt slows down.

During the positive phases of the cycle, leverage increased persistently in the years preceding both the crisis of the European monetary system (1992-93) and the dot-com bust (2001-03), while there is no clear leveraging pattern before the double-dip busts following the great financial crisis (2008-09 and 2011-13). These differences can be explained by the different length of economic expansions: 1983-1991 and 1994-2000 (albeit with a mild downturn in 1996) compared to 2004-07.

Figure 2 confirms these relations using a quantitative measure of the business cycle. Leverage tends to increase during busts (panel a, left) as the lower contribution of debt (panel b, left) is larger than that of equity (panel c, left). The positive correlation between busts and debt is higher with a lag (panel b), while the contemporaneous and lagged cyclicality of equity is similar (panel c). 
Figure 1 - Change of leverage and contribution of debt and equity (percentage points)

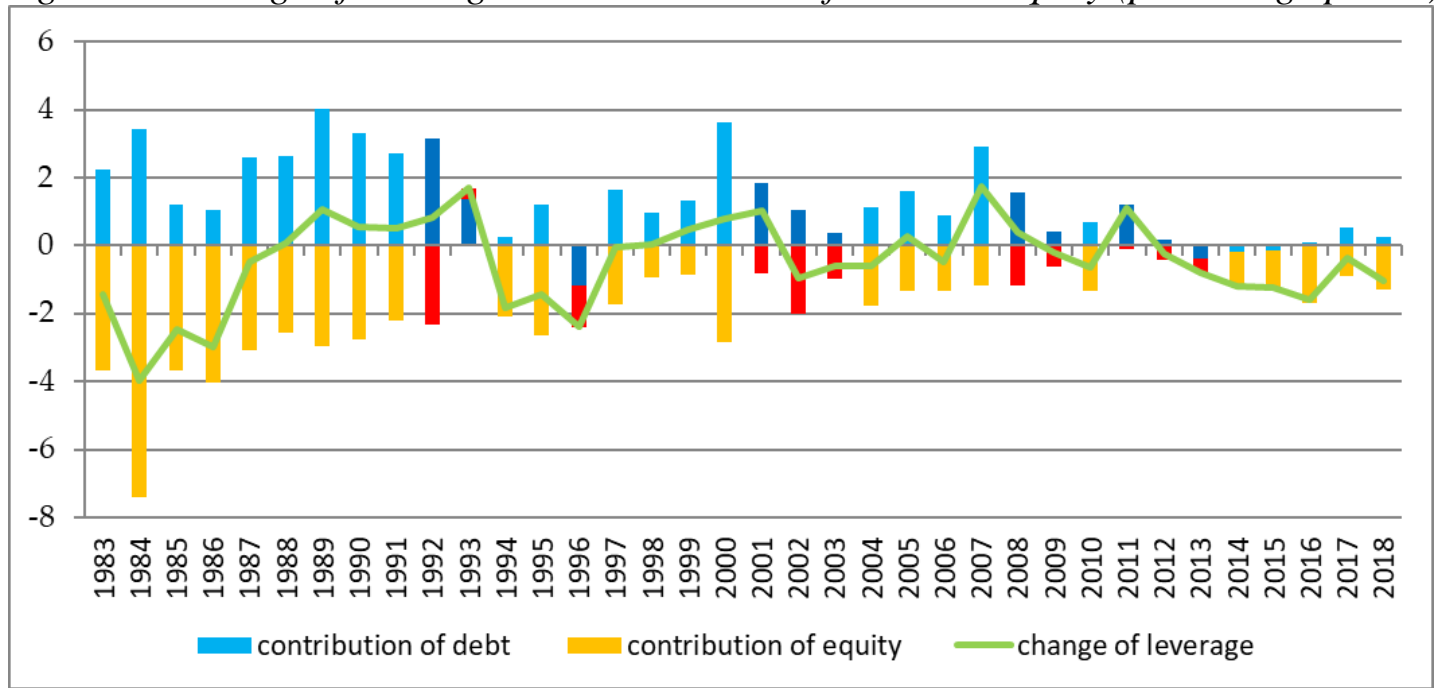

Figure $2-G D P$, change of leverage and contribution of debt and equity (percentage points) a) change of leverage
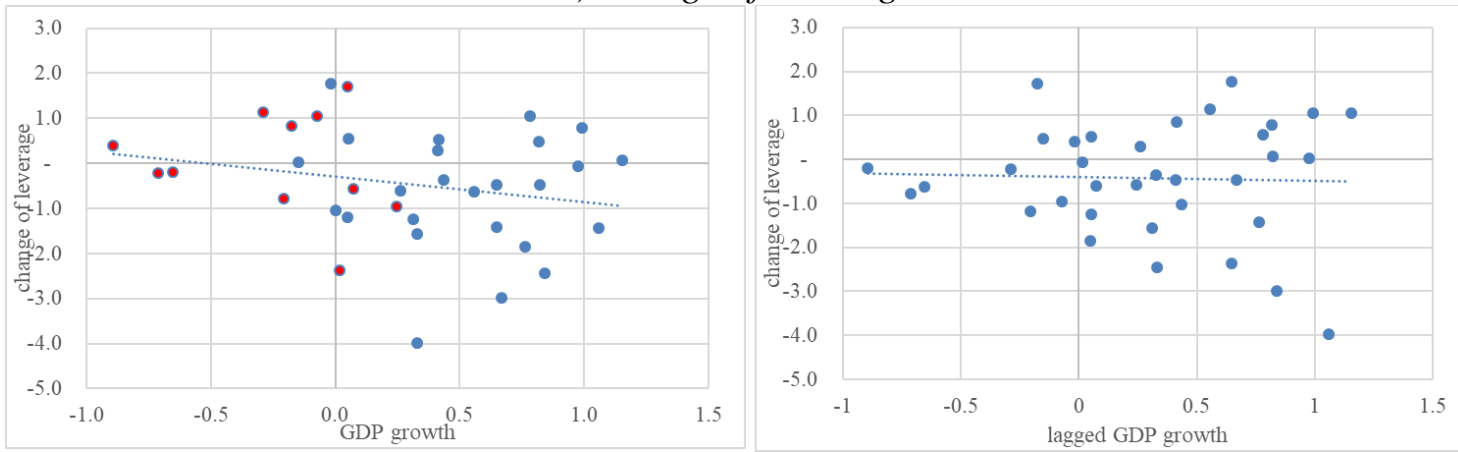

b) contribution of debt

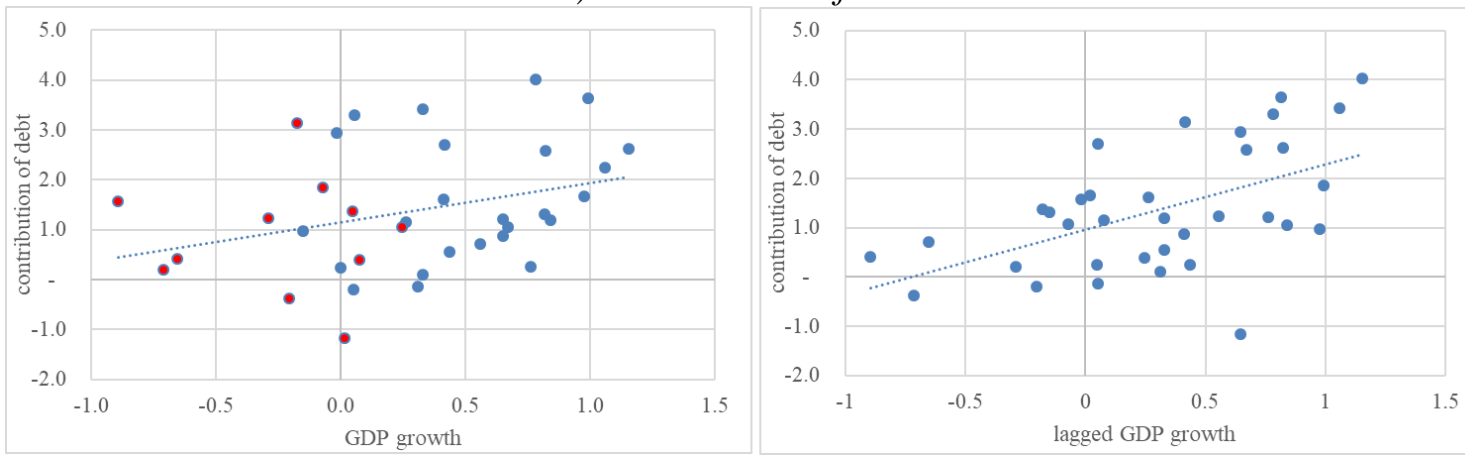

c) contribution of equity
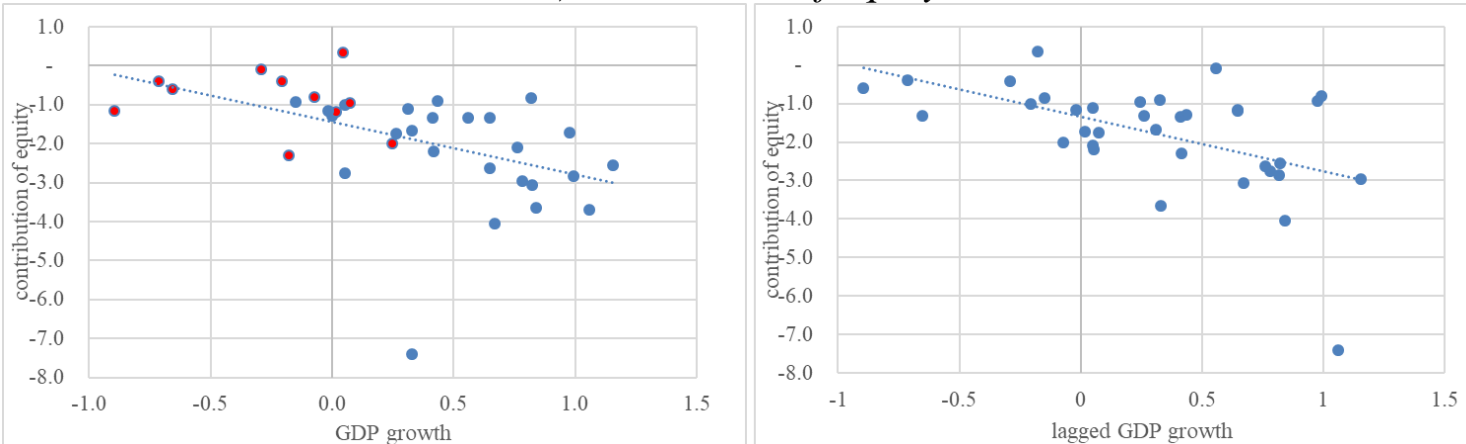

Note: The X-axis shows the yearly average of the four quarterly GDP growth rates and the change of leverage (panel a), the contribution of debt (panel b) and that of equity (panel c); the contemporaneous relationships are shown on the left (slumps are identified by red circles) and lagged ones on the right. 
The existence of deleveraging patterns after each bust (1980-1982, 1992-93, 2001-3 and 200809/2011-13), especially after the second and the fourth, is also linked to some specific dynamics of equity.

Figure 3 shows the yearly deflated percentage change of equity and its four components, with the main aim of evaluating the relevance of retained earnings. ${ }^{5}$ It is clear that most of the variation over time is not due to change of shareholders' funds or reserves (apart in some specific years like 1983, 1984, 1992, 1999, 2000), but to large and volatile profits only partially compensated by small and more stable dividends. Profits are positive and somehow increasing before busts and declining thereafter (they are even negative in 1983 and in 1992-93), while dividends are a relatively stable share of equity. The pay-out ratio (dividend/profits) is countercyclical: indeed, retained earnings are negative in 1983, 1991-94, 2001-02, 2009 and 2011-13.

After busts, the recovery of profits, combined with a persistent lower level of dividends and a relatively stagnant contribution of debt, drives the rebalancing of firms financial structure. This pattern is particularly clear after the European monetary system and the global/euro area crises: the ratio of dividends to lagged capital was on average around 5 per cent between 1984-1990 and 200408, while it went down to 2.5 and 3.5 per cent between 1992-97 and 2009-18, respectively.

Figure 3 - Contributions to the rate of change of deflated equity (percentage points)

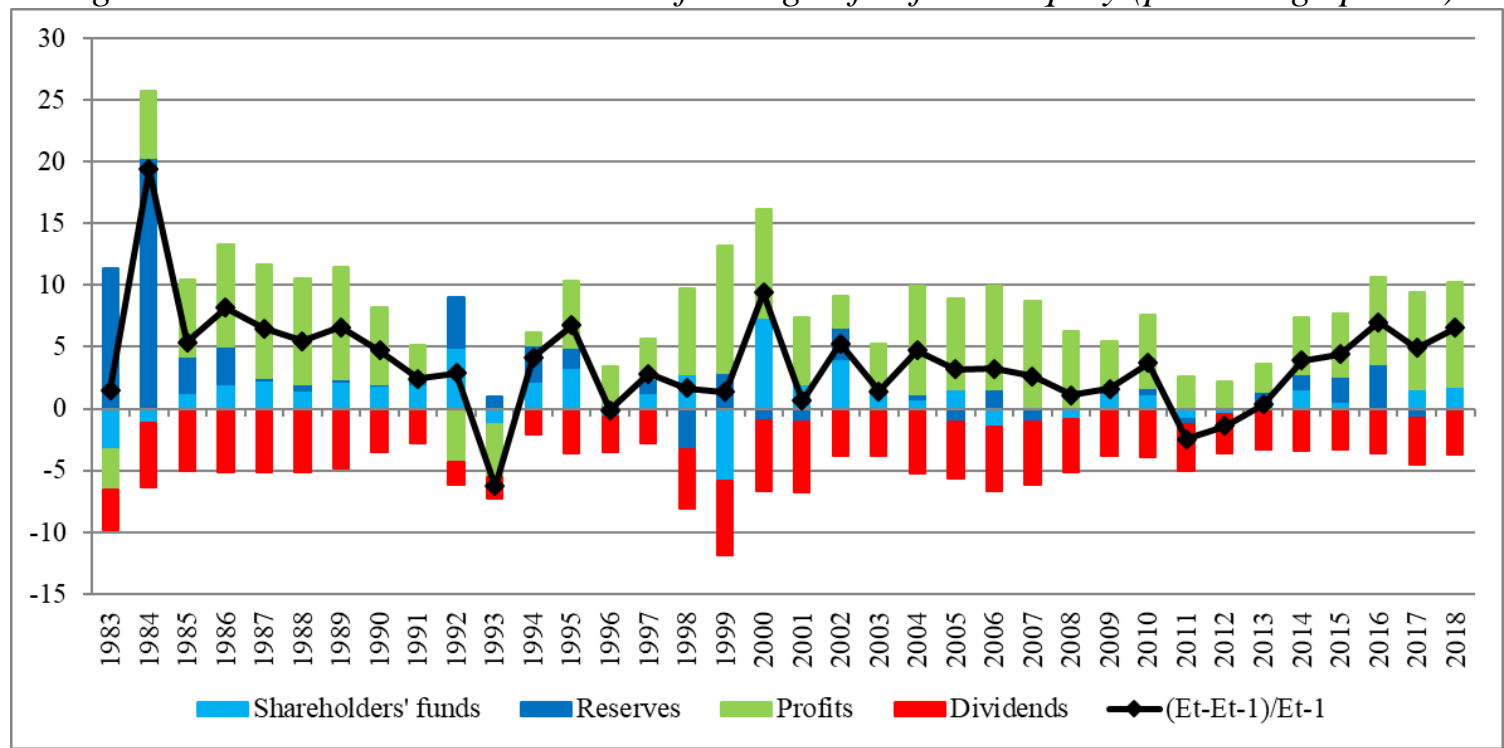

${ }^{5}$ See equation (c). All values are expressed in real 2003 euro. 


\subsection{Correlations by size, age, profitability, riskiness, and debt structure}

The previous literature on the relation between leverage and the business cycle highlighted the role of few very large firms when aggregate dynamics are evaluated. This finding is confirmed in Italy, also because very large companies (the top centile of the size distribution by assets, consisting of around 200-700 companies depending on the year) had a peculiar financial structure compared to other firms. They were highly leveraged at the beginning of the '80s (Banca d'Italia, 1981), strengthened their financial structure in the first years of that decade (Banca d'Italia, 1985) and also in the second part of the Nineties (Varetto, 2005) so that their leverage nearly halved between 1982 and 1997 (for more details see Appendix A4).

A preliminary assessment of the role of size follows the previous literature by creating 10 classes, based on assets deciles calculated every year. Table 1A shows the unconditional correlations between the change of leverage and the contributions of debt and equity with the business cycle both contemporaneously (BUST) and after one year $\left(\mathrm{BUST}_{+1 \mathrm{Y}}\right)$; aggregate correlations for the whole sample of firms (first row) are then exploded distinguishing by size classes. The change of leverage or the contribution of debt (equity) is procyclical if the correlation is negative (positive).

Interestingly, there appear to be more similarities among smaller (I-III decile) and very large firms ( $\mathrm{X}$ decile) than those belonging to central classes (IV-IX decile). More specifically, the main features are the following:

1) Overall leverage tends to increase during busts (the contemporaneous correlation is 0.23 , while the lagged one is negligible), but heterogeneity across size classes is large. While the contemporaneous correlation is quite low for smallest firms (I decile), it turns out being slightly positive for the other extremes of the size distribution, i.e. for small and very large firms (II, III and $\mathrm{X}$ decile), and negligible for the others. The lagged correlation is instead close to zero for all extreme classes and negative for the central ones (IV-IX decile). These findings imply that leverage dynamics during busts for the majority of firms (7 classes out of 10) are entirely different from the aggregate one.

2) The correlation with debt is procyclical and is higher with a lag. Values are lower for the extreme classes (I-III and X decile) and quite high (around or above 50 per cent) for the central size classes one year after the beginning of the slump.

3) Equity is procyclical as well; differently from debt, the correlation is higher contemporaneously and remains quite high with a lag; similarly to debt, correlations are lower for the I and X decile, but larger for all the other classes.

Summing up, these findings suggest that for central classes (IV-IX decile) the contributions of debt and equity cancel out during busts (therefore the correlation is negligible), while after one year the former overwhelms the latter so that leverage goes down. For the other size classes, the correlations are lower and the picture is more mixed; the contemporaneous increase of leverage for smaller firms (II-III decile) can be ascribed to the higher procyclicality of equity compared to that of debt. 
Table 1A - Correlation between busts and change of leverage, debt and equity (by size)

\begin{tabular}{|c|c|c|c|c|c|c|c|}
\hline & & \multicolumn{2}{|c|}{ change of leverage } & \multicolumn{2}{|c|}{ contribution of debt (a) } & \multicolumn{2}{|c|}{ contribution of equity (b) } \\
\hline & & BUST & $\mathrm{BUST}_{1 \mathrm{Y}}$ & BUST & $\mathrm{BUST}_{1 \mathrm{Y}}$ & BUST & $\mathrm{BUST}_{1 \mathrm{Y}}$ \\
\hline \multirow{13}{*}{$\begin{array}{l}\text { TOTAL } \\
\text { Size (deciles) }\end{array}$} & & 0.23 & -0.04 & -0.27 & -0.41 & 0.45 & 0.34 \\
\hline & I & 0.00 & -0.15 & -0.20 & -0.12 & 0.29 & -0.06 \\
\hline & II & 0.10 & -0.10 & -0.17 & -0.29 & 0.56 & 0.34 \\
\hline & III & 0.21 & -0.07 & -0.20 & -0.35 & 0.73 & 0.47 \\
\hline & IV & -0.12 & -0.34 & -0.36 & -0.49 & 0.71 & 0.55 \\
\hline & $\mathrm{V}$ & 0.03 & -0.22 & -0.30 & -0.52 & 0.61 & 0.54 \\
\hline & VI & -0.02 & -0.31 & -0.37 & -0.55 & 0.58 & 0.51 \\
\hline & VII & 0.05 & -0.21 & -0.37 & -0.51 & 0.62 & 0.51 \\
\hline & VIII & 0.03 & -0.24 & -0.32 & -0.48 & 0.55 & 0.48 \\
\hline & IX & -0.03 & -0.28 & -0.37 & -0.49 & 0.53 & 0.48 \\
\hline & $\mathrm{X}$ & 0.22 & 0.03 & -0.19 & -0.29 & 0.40 & 0.29 \\
\hline & I-IX & 0.02 & -0.27 & -0.36 & -0.52 & 0.59 & 0.51 \\
\hline & TOP 1 & 0.18 & 0.07 & -0.14 & -0.18 & 0.33 & 0.24 \\
\hline
\end{tabular}

Note: The first, third and fifth column show the contemporaneous correlation between a dummy (BUST) identifying contractionary years $(1992-93,1996,2001-03,2008-09,2011-13)$ and the change of leverage or the contribution of debt or equity; the second, fourth and sixth column show the lagged correlation, shifting the dummy one year ahead (BUST $+1 Y)$. Values in red are higher than the average value (TOTAL) by more than 10 percentage points.

(a) A negative correlation means that debt is procyclical: during busts the positive contribution of debt to leverage is lower (i.e. the growth of debt is lower with respect to expansionary years) or even negative. - (b) A positive correlation means that equity is procyclical: during busts the negative contribution of equity to leverage is lower (i.e. the growth of equity is lower with respect to expansionary years) or even positive.

The heterogeneity of the relation between leverage and the business cycle depend also on other firms' characteristics that may affect differently the reaction of equity or debt during busts. This issue is quite relevant, because size could proxy for other variables: for instance, smaller firms could be younger, less profitable, riskier and more dependent on short-term or bank debt. The heterogeneity of the relation between leverage and business cycles due to these variables can be summarised as follows (Table 1B; more details are presented in Appendix A4):

1) the leverage of old companies tends to increase during busts, mainly due to equity contribution, while young firms are characterized by more erratic changes that are lowly correlated with the business cycle;

2) the leverage of firms with negative EBITDA is positively correlated with busts, especially contemporaneously;

3) leverage dynamics of sound firms are similar but less pronounced than the aggregate, while risky ones show one of the highest positive correlation with busts, driven by equity contribution contemporaneously and debt influence with a lag;

4) the leverage of companies relying only on short term funding is negatively correlated with busts with a lag, as the lower contribution of debt is one of the highest;

5) firms relying only on bank funding have different cyclicality compared to less dependent firms: the relation with busts is negative, driven by a stronger decline of debt.

Summing up, there is a particularly high positive contemporaneous relation between leverage and busts for old and unprofitable firms; the negative lagged correlation is higher for companies entirely dependent on bank-debt. For risky firms and those depending on short-term debt the correlations 
remain instead positive and negative, respectively. Overall, such dynamics are more related to equity (age and profitability), debt (share of short-term or bank funding) or both (riskiness).

Table $1 B$ - Correlation between busts and change of leverage, debt and equity (other characteristics)

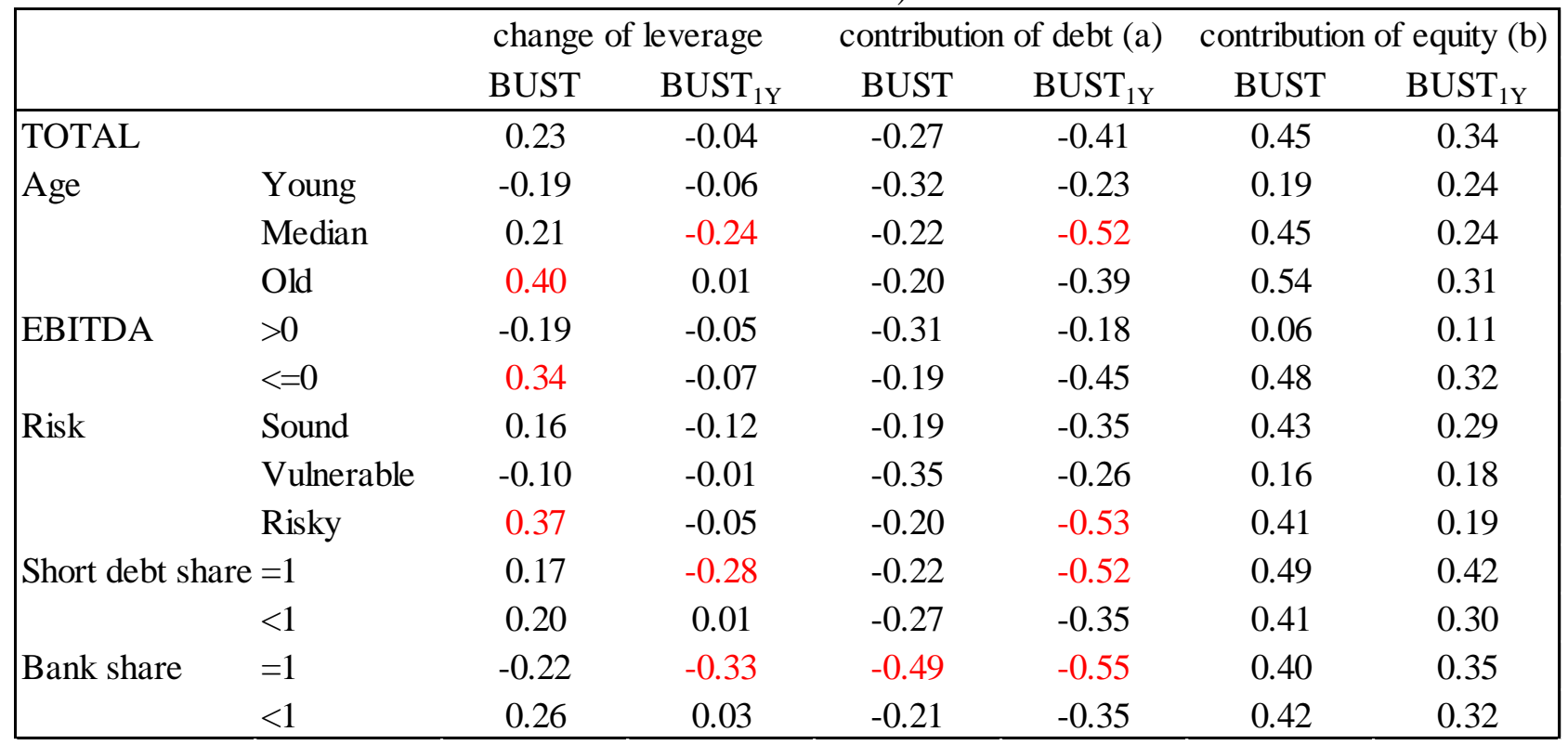

Note: The first, third and fifth column shows the contemporaneous correlation between a dummy (BUST) identifying contractionary years $(1992-93,1996,2001-03,2008-09,2011-13)$ and the change of leverage or the contribution of debt or equity; the second, fourth and sixth column shows the lagged correlation, shifting the dummy one year ahead $\left(\right.$ BUST $_{+1 Y}$ ). Values in red are higher than the average value (TOTAL) by more than 10 percentage points.

(a) A negative correlation means that debt is procyclical: during busts the positive contribution of debt to leverage is lower (i.e. the growth of debt is lower with respect to expansionary years) or even negative. - (b) A positive correlation means that equity is procyclical: during busts the negative contribution of equity to leverage is lower (i.e. the growth of equity is lower with respect to expansionary years) or even positive.

\section{Leverage and business cycle: regression analysis}

The two main findings of the previous Section are that: a) a few very large companies drive the aggregate dynamics and correlations; b) the heterogeneity among firms is not limited to size. These results rely on weighted means and are therefore influenced by the largest companies in each group. A complementary firm-level evaluation based on regression analysis avoids this issue and helps to highlight the role of size controlling for other firm characteristics.

Figure 4 shows the main descriptive statistics of the yearly change of leverage during the time span under analysis (Appendix A5 shows details for debt and equity contributions). The distribution is symmetric around a median value of zero, also during busts; the dispersion decreased since the second half of the Nineties, possibly due to the decline of growth rate of the Italian economy and the consequential lower investment needs and desired changes of the financial structure. The mean is slightly positive, especially during busts (aggregate dynamics based on weighted means are instead slightly negative). 


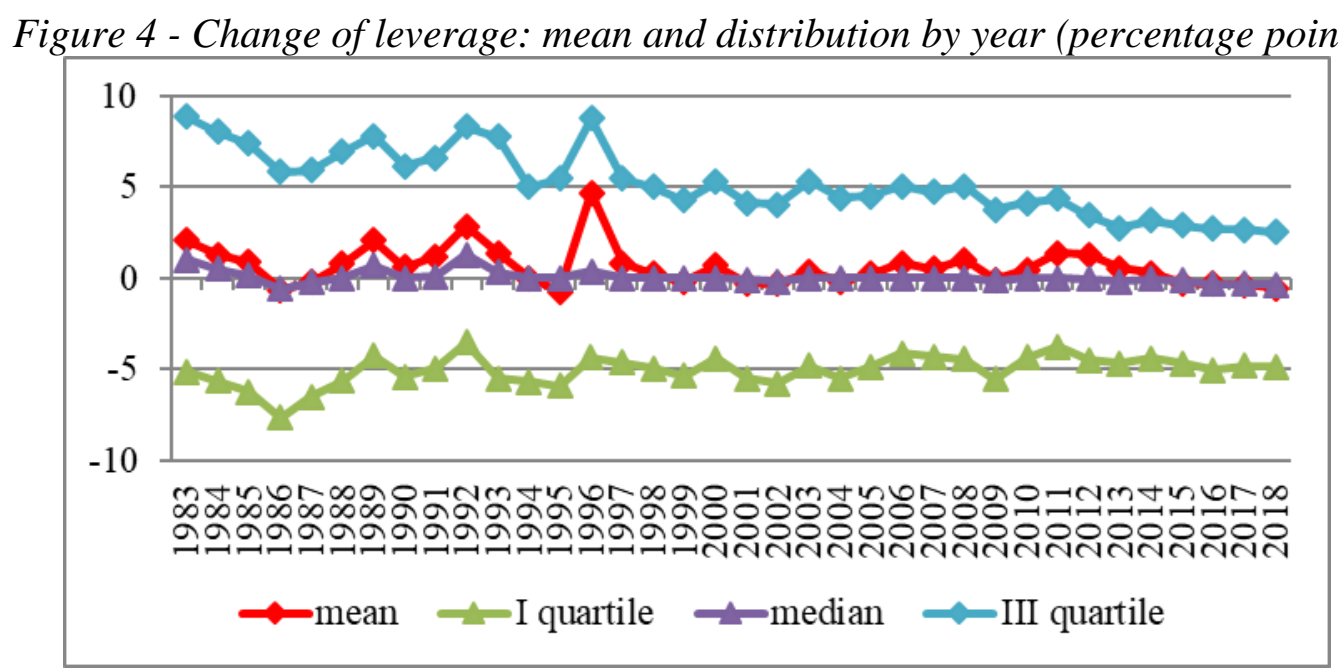

Table 2 summarises the contemporaneous and lagged relation between business cycles and firms' financial structure examined in the subsequent regression analyses. The yearly change of leverage and of its two components during busts $(\mathrm{BUST}=1)$ or one year after its beginning $\left(\mathrm{BUST}_{+1 \mathrm{Y}}=1\right)$ is compared to the respective remaining reference years, confirming that the increase of leverage is markedly higher during busts ( 1.02 versus 0.31 percentage points) but lower with a lag ( 0.42 versus 0.64 percentage points). A direct comparison between the contemporaneous and lagged means (1.02 and 0.42 percentage points) confirms that the difference is due more to the lower contribution of debt (from 0.95 to 0.64 percentage points) than that of equity ( -0.07 and -0.35 percentage points).

Table 2 - Mean change of leverage and its components (percentage points)
\begin{tabular}{|lccc|}
\hline & change of leverage & contribution of debt & contribution of equity \\
\hline $1983-2016$ & 0.56 & 1.29 & -0.90 \\
BUST $=1$ & 1.02 & 0.95 & -0.07 \\
BUST $=0_{2}$ & 0.31 & 1.48 & -1.35 \\
BUST $_{+1 Y}=1$ & 0.42 & 0.64 & -0.35 \\
BUST $_{+1 \mathrm{Y}}=0$ & 0.64 & 1.66 & -1.20 \\
\hline
\end{tabular}

\subsection{Results on the entire sample}

Table 3 reports the results of regressions (1-6), which confirm the dynamics derived from the correlation analysis: compared with booms, leverage increases more during busts and less with a lag, mainly reflecting the delayed dynamic of $\mathrm{debt}^{6}$.

The values of the Constant represent the means of the three dependent variables during booms (the reference period). The change of leverage is slightly positive ( 0.29 percentage points; col. 1$)$, as the positive contribution of debt (1.43 percentage points; col.2) is larger than the negative contribution of equity (-1.32 percentage points; col. 3). The dummies BUST measure the deviation from such means, i.e. the difference between busts and booms. The signs confirm that leverage increases more during slumps (0.77 percentage points; col. 1) because the contribution of debt is lower $(-0.40$

${ }^{6}$ Results are confirmed using a different set of regressions that distinguish booming years into those closer to a through and those closer to a peak (see Appendix A5). 
percentage points; col. 2), but is overwhelmed by the change of the contribution of equity (1.20 percentage points; col. 3). A comparison between the signs and point estimates of the dummies BUST and BUST+1Y confirms that leverage grows slightly less with a lag (col. 4:-0.12 versus col. 1:0.77), because the markedly lower contribution of debt (col. 5:-0.93 versus col. 2:-0.40) more than compensates a closer contribution of equity (col. 6:0.86 versus col. 3:1.20).

Table 3 - Business cycles and leverage, debt and equity

\begin{tabular}{|lcccccc|}
\hline VARIABLES & $(1)$ & $(2)$ & $(3)$ & $(4)$ & $(5)$ & $(6)$ \\
\hline BUST & DLEV & DF & EQ & DLEV & DF & EQ \\
& $0.765^{* * *}$ & $-0.399^{* * *}$ & $1.196^{* * *}$ & & & \\
BUST $_{+1 Y}$ & $(0.0301)$ & $(0.0255)$ & $(0.0180)$ & & & \\
& & & & $-0.115^{* * *}$ & $-0.928^{* * *}$ & $0.861^{* * *}$ \\
Constant & & & & $(0.0293)$ & $(0.0249)$ & $(0.0174)$ \\
& $0.289^{* * *}$ & $1.431^{* * *}$ & $-1.321^{* * *}$ & $0.602^{* * *}$ & $1.624^{* * *}$ & $-1.207^{* * *}$ \\
& $(0.0107)$ & $(0.00904)$ & $(0.00637)$ & $(0.0105)$ & $(0.00896)$ & $(0.00624)$ \\
Observations & 1665896 & 1665896 & 1665896 & 1665896 & 1665896 & 1665896 \\
R-squared & 0.000 & 0.000 & 0.003 & 0.000 & 0.001 & 0.002 \\
Number of firms & 165813 & 165813 & 165813 & 165813 & 165813 & 165813 \\
\hline
\end{tabular}

\subsection{Results by groups of firms (size, age, profitability, riskiness, debt structure)}

Figure 5 shows for each group of firms the results of regressions (1-6), i.e. the estimated coefficients for the relations during slumps contemporaneously (i.e. $\beta_{1 \approx} \beta_{2}+\beta_{3}$ ) with a lag (i.e. $\beta_{4 \approx} \beta_{5}+\beta_{6}$ ) or during booms (i.e. $\mathrm{a}_{1} \approx \mathrm{a}_{2}+\mathrm{a}_{3}$ ). The main results are confirmed but heterogeneity is large. ${ }^{7}$

During years of slump leverage has a U-shaped relation with size (Figure 5.a): the smaller and the largest companies (I-III and X decile) tend to increase their leverage more than other firms, but the underlying forces differ. For the smaller companies the reduction of equity is more important (green histograms are higher compared to other deciles), while for the largest group the smaller decrease of debt is relevant (compared to closest deciles, green histograms are similar but red histograms are smaller), suggesting that the latter continue to access the credit or bond markets more than other companies. The second main finding is that leverage increase more for risky and unprofitable firms, due to lower profitability.

The negative lagged relation between busts and leverage depends on contribution of debt that mostly overwhelms that of equity in all groups and especially for larger firms (IV-X decile); leverage remains stable for smaller firms (I-III decile), decreases more for young firms, while continues to increase for riskier and unprofitable companies (Figure 5.b).

During expansionary years leverage has an inverted U-shaped relation with size, so that the middle-sized companies (IV-IX decile) increase their debt and leverage slightly more (Figure 5.c). Two other firm characteristics stand out: the leverage of unprofitable and risky firms goes up the most, as equity declines for both; however for the latter debt increases, suggesting that financial frictions are lower for marginal borrowers during booms.

\footnotetext{
${ }^{7}$ Appendix A5 shows results by sector of economic activity.
} 
Figure 5 - Estimates of change of leverage and of its components (percentage points) a) contractionary years (dummy BUST)

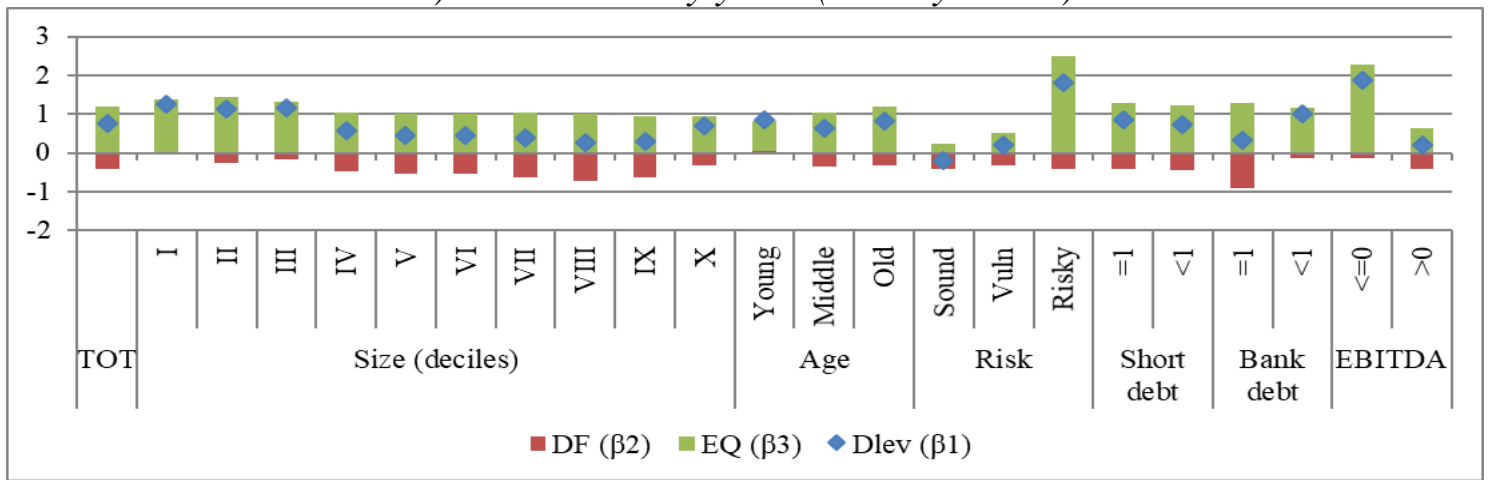

b) contractionary years one year later (dummy BUST $+1 Y$ )

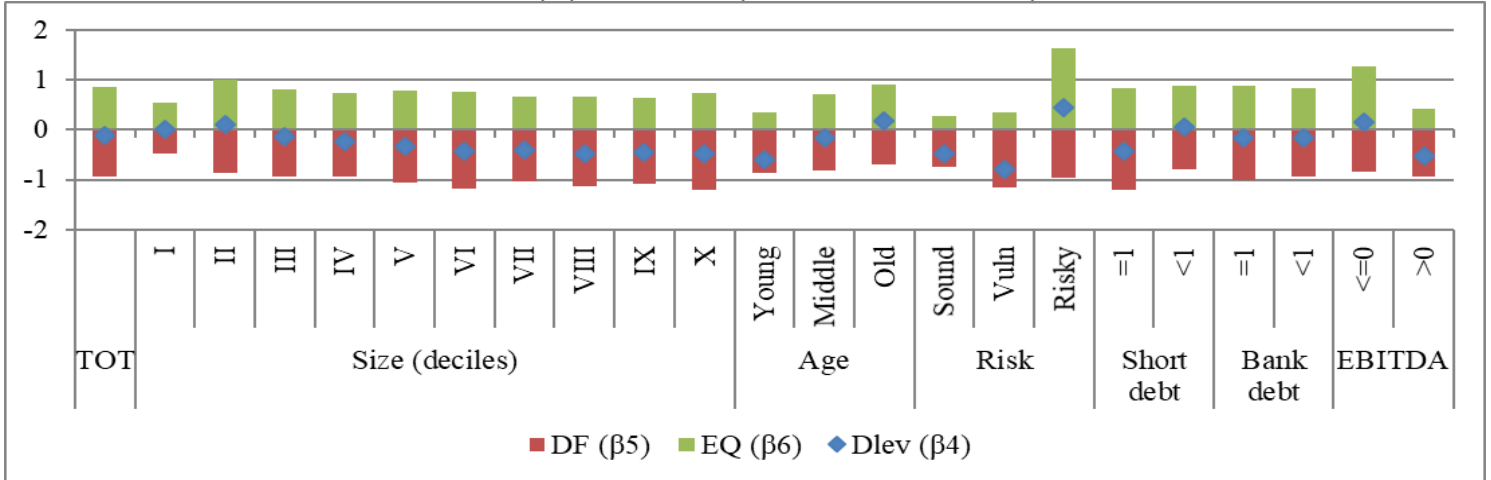

c) out of busts (Constant)

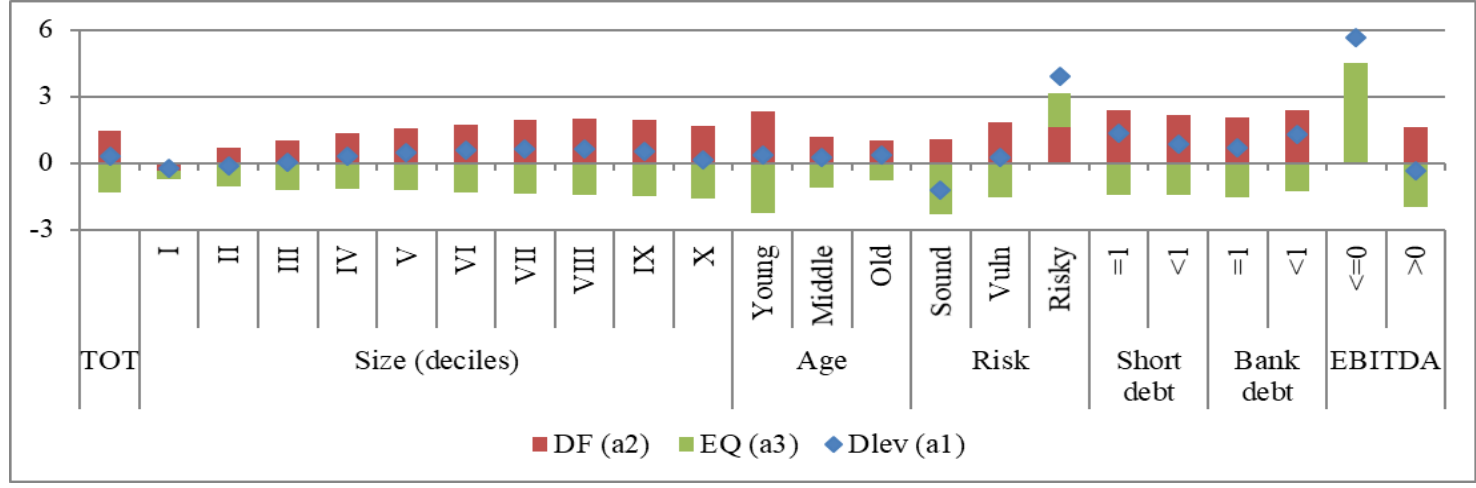

\subsection{The role of size controlling for other characteristics}

The previous set of regressions show that size and other firms characteristics separately influence the contemporaneous and lagged dynamics of leverage during slumps.

Figure 6 summarises the main results of specifications A1/A2 and B1/B2, which include contemporaneously all firms and variables. For each size class "s", the estimated coefficients $\beta_{\mathrm{S}}$ is shown, i.e. the interaction terms between size deciles and slumps (contemporaneously or one year ahead) with and without controls; the point estimates are not perfectly comparable among specifications because the reference class is different, ${ }^{8}$ but they are remarkably similar.

\footnotetext{
${ }^{8}$ The reference class in regressions A1 (A2) is the first decile by size if BUST (BUST $+1 Y$ ) is equal to 0 . The reference class in regressions B1 and B2 includes as additional conditions firms being young, safe, unprofitable and with shares of bank and short term debt lower than 100 per cent.
} 
The two main results regarding size classes remain in both specifications: during a bust there is a U-shaped relation as leverage increases more for smaller (I-III decile) and largest companies (X decile; figure 6.A); financial structure of smaller firms improves less with a lag (Figure 6.B).

Moreover, the differences of the estimated coefficients with respect to the I decile (which has the extreme behaviour in all specifications) are similar, with one relevant exception: the contribution of equity during a bust. The estimated coefficients become indeed similar when other variables are included in the estimations (green histograms in Figure 6.A2 versus Figure 6.A1), meaning that the heterogeneity by size classes is in part due to other firms characteristics.

Figure 6 - Change of leverage and of its components by size classes (percentage points)

A1) bust\&without controls

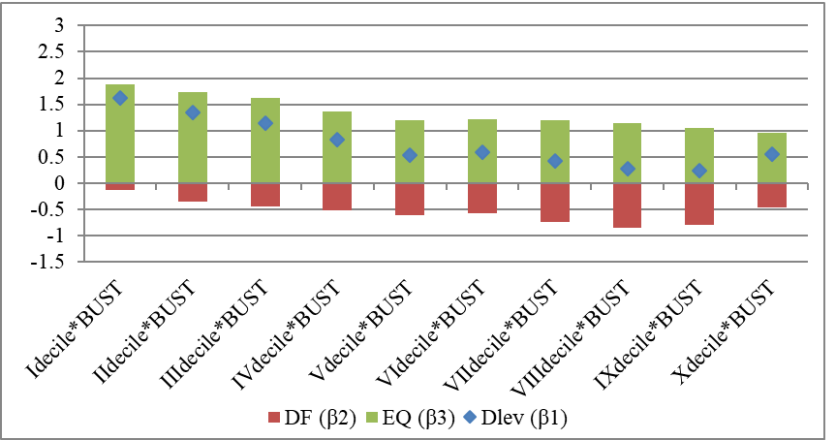

B1) lagged bust\&without controls

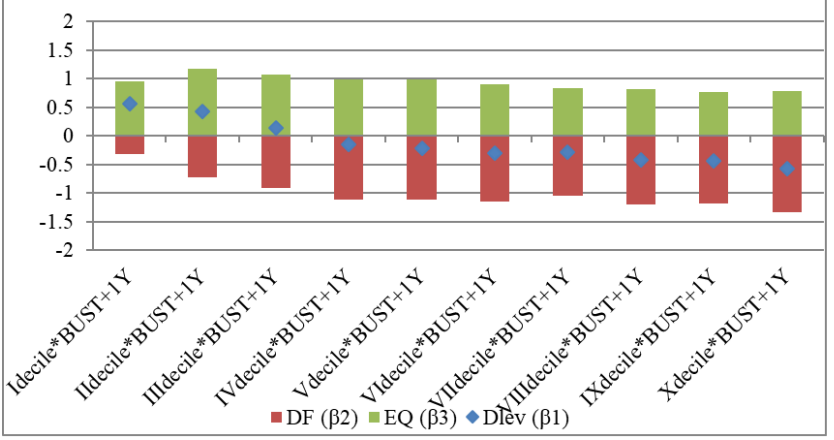

\section{A2) bust\&controls}

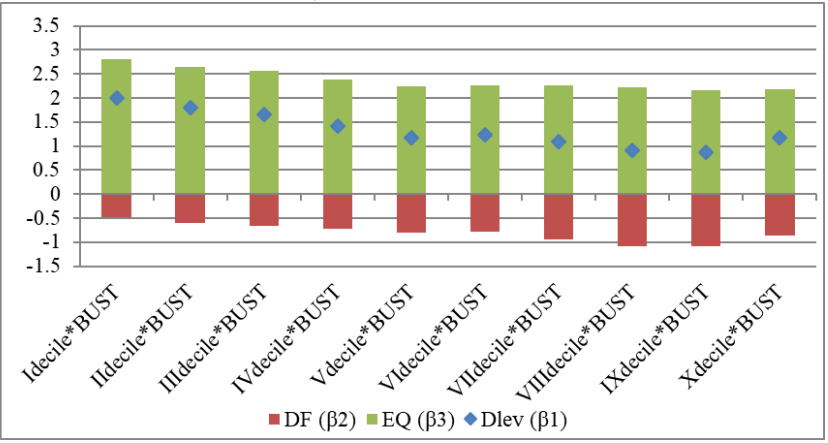

B2) lagged bust\&controls

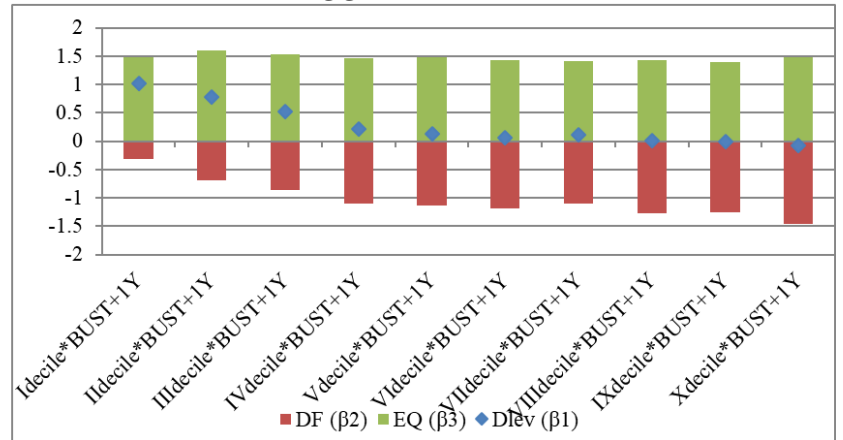

\subsection{A deeper evaluation of the role of profits}

The analyses presented so far show that equity provides an important and persistent contribution to leverage dynamics; on the base of the descriptive analyses of Section 3.1, profits represent a key determinant of equity and it is therefore interesting to evaluate more in details the relations among the different components of equity and the business cycle.

Table 4 summarises the estimations of regressions $1^{\mathrm{e}}$ to $10^{\mathrm{e}}$. The three main results are the following. First, profits are the key driver of the change in equity growth during slumps (dummy BUST in column 4E is similar to $1 \mathrm{E}$ ), booms (Constant in column 4E is similar to $1 \mathrm{E}$ ) and after a bust (dummy BUST $+\mathbf{+ 1}$ in column 9E is similar to 6E). Second, the estimated values of BUST and BUST $_{+1 Y}$ are close for all the dependent variables, suggesting that the negative effect of a slump on equity is somehow persistent. Third, the reduction in the growth rate of equity in a slump due to lower profits (-5.4 percentage points; column 4) overwhelms the somehow higher contribution coming from dividends $(+0.3$ percentage points; column 5), confirming that the fall of profitability during a bust cannot be compensated by lower dividends. 
Table 4-Business cycles and equity components

\begin{tabular}{|c|c|c|c|c|c|c|c|c|c|c|}
\hline VARIABLES & $\begin{array}{l}\text { (1E) } \\
\text { Equity } \\
\text { growth }\end{array}$ & $\begin{array}{c}(2 \mathrm{E}) \\
\text { Shareholders } \\
\text { funds }\end{array}$ & $\begin{array}{c}(3 \mathrm{E}) \\
\text { Reserves }\end{array}$ & $\begin{array}{c}(4 \mathrm{E}) \\
\text { Profits }\end{array}$ & $\begin{array}{c}(5 \mathrm{E}) \\
\text { Dividends }\end{array}$ & $\begin{array}{l}\text { (6E) } \\
\text { Equity } \\
\text { growth }\end{array}$ & $\begin{array}{c}(7 \mathrm{E}) \\
\text { Shareholders } \\
\text { funds }\end{array}$ & $\begin{array}{c}(8 \mathrm{E}) \\
\text { Reserves }\end{array}$ & $\begin{array}{c}(9 \mathrm{E}) \\
\text { Profits }\end{array}$ & $\begin{array}{c}\text { (10E) } \\
\text { Dividends }\end{array}$ \\
\hline BUST & $\begin{array}{c}-4.148 * * * \\
(0.0636)\end{array}$ & $\begin{array}{c}-0.386^{* * * *} \\
(0.0188)\end{array}$ & $\begin{array}{l}1.151^{* * *} \\
(0.0269)\end{array}$ & $\begin{array}{c}-5.391 * * * \\
(0.0536)\end{array}$ & $\begin{array}{l}0.342^{* * * *} \\
(0.00415)\end{array}$ & & & & & \\
\hline $\mathrm{BUST}_{+1 \mathrm{Y}}$ & & & & & & $\begin{array}{c}-3.111^{* * *} \\
(0.0625)\end{array}$ & $\begin{array}{c}0.178^{* * * *} \\
(0.0187)\end{array}$ & $\begin{array}{c}0.513 * * * \\
(0.0267)\end{array}$ & $\begin{array}{c}-4.120 * * * \\
(0.0514)\end{array}$ & $\begin{array}{l}0.348 * * * \\
(0.00411)\end{array}$ \\
\hline Constant & $\begin{array}{l}11.52 * * * \\
(0.0226)\end{array}$ & $\begin{array}{l}3.333 * * * \\
(0.00666)\end{array}$ & $\begin{array}{l}-2.038 * * * \\
(0.00955)\end{array}$ & $\begin{array}{l}11.14 * * * \\
(0.0190)\end{array}$ & $\begin{array}{l}-0.844 * * * \\
(0.00147)\end{array}$ & $\begin{array}{l}11.17^{* * *} \\
(0.0225)\end{array}$ & $\begin{array}{l}3.132 * * * \\
(0.00674)\end{array}$ & $\begin{array}{l}-1.814 * * * \\
(0.00959)\end{array}$ & $\begin{array}{c}10.72^{* * *} \\
(0.0185)\end{array}$ & $\begin{array}{c}-0.848^{* * *} \\
(0.00148)\end{array}$ \\
\hline $\begin{array}{l}\text { Observations } \\
\text { R-squared } \\
\text { Number of firms }\end{array}$ & $\begin{array}{c}1665482 \\
0.003 \\
165790\end{array}$ & $\begin{array}{c}1665482 \\
0.000 \\
165790\end{array}$ & $\begin{array}{c}1665482 \\
0.001 \\
165790\end{array}$ & $\begin{array}{c}1665482 \\
0.009 \\
165790\end{array}$ & $\begin{array}{c}1665482 \\
0.005 \\
165790\end{array}$ & $\begin{array}{c}1665482 \\
0.002 \\
165790\end{array}$ & $\begin{array}{c}1665482 \\
0.000 \\
165790\end{array}$ & $\begin{array}{c}1665482 \\
0.000 \\
165790\end{array}$ & $\begin{array}{c}1665482 \\
0.005 \\
165790\end{array}$ & $\begin{array}{c}1665482 \\
0.005 \\
165790\end{array}$ \\
\hline
\end{tabular}

Figure 7 presents the core evidence from regressions $\mathrm{A} 1^{\mathrm{e}}$ and $\mathrm{B} 1^{\mathrm{e}}$, which aim to assess the importance of profits as drivers of equity dynamics distinguishing by size classes without and with other control variables, respectively. The three main results are the following. First, without control variables the real changes of equity during busts with respect to booms (black circles in fig. 7A) are lower for all size classes, especially for smaller firms (I-III decile). Second, the cross-size differences becomes smaller but persists when other control variables are included in the regressions (black circles in Fig. 8.B). Third, these dynamics are driven by profits, which decrease more for smaller firms with respect to larger ones during busts (red squares in Fig. 8.A), also controlling for other variables (red squares in Fig. 8.B). ${ }^{9}$

Figure 7 - Rate of change of equity and profits by size classes (percentage points)
A) bust \&without controls
B) bust\&controls
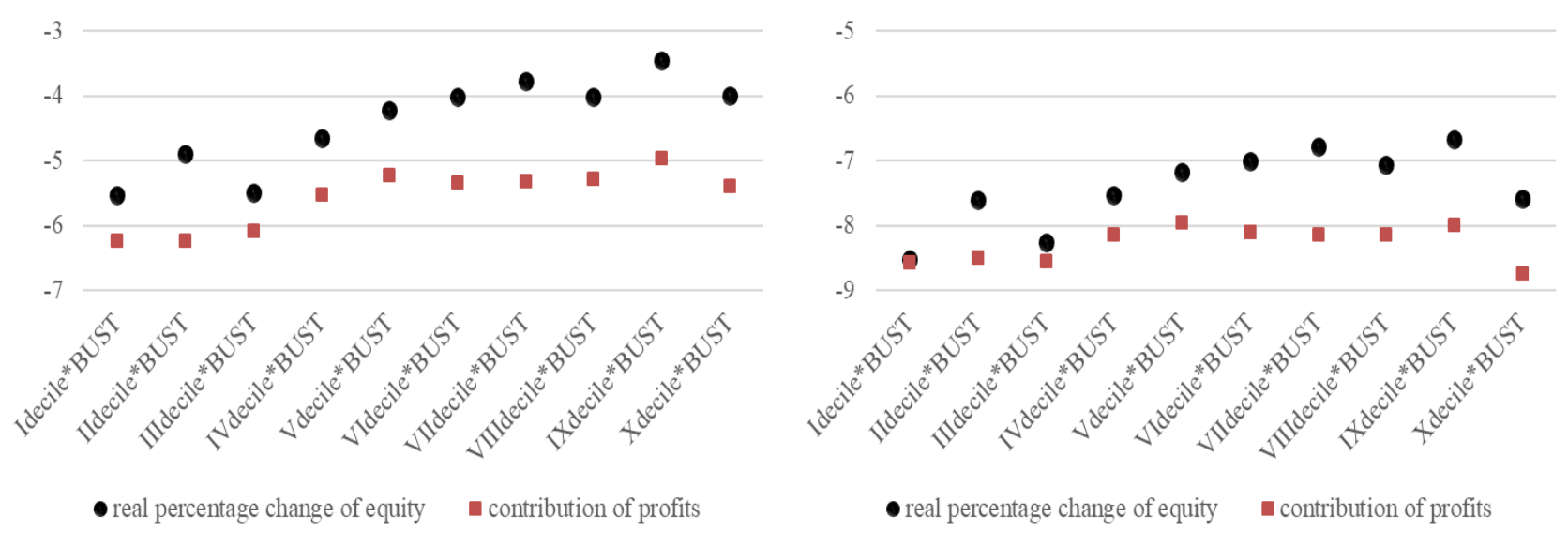

${ }^{9}$ I report the estimated coefficients of the real percentage change of equity and the contribution of profits because other contributions are negligible. 


\section{Discussion of main findings and future developments}

This paper examines the relationship between business cycles and leverage in Italy focusing on the role of size and other firm characteristics related to financial frictions such as age, risk, profitability and debt structure. The analysis is mainly based on unlisted SMEs and therefore the conclusions about the cyclical dynamics of debt and equity are more general compared to the previous literature.

The study disentangles the relative contributions of debt and equity to the changes of leverage, both at the aggregate level and for specific groups of firms, relying on a descriptive analysis (based on weighted means) and a regression analysis (based on simple means). Reassuringly the results of the two approaches are similar, even if the change of leverage over the entire time span is slightly negative (positive) when weighted (simple) means are considered.

Both analyses based on the entire sample (Sections 3.1 and 4.1) find that leverage tends to increase during busts mainly due to lower equity growth, and to decrease after one year as debt growth goes down or becomes even negative. The influence of equity dynamics on leverage during busts is more persistent, as it depends on the overwhelming contribution of procyclical profits, while the role of shareholders' funds is limited.

The role of size is clear when the extreme classes are considered (Sections 3.2 and 4.2): weighted averages show that very large firms (top 1 percent) drive the aggregate results, and the $\mathrm{X}$ decile determines the dynamics of leverage. Correlation and regression analyses find some new results: the relation between busts and leverage is more similar for smaller and largest firms (I-III and X decile) compared to median ones (IV-IX decile), even if the financial structure of the I decile is less correlated with business cycle.

During expansionary periods the change of leverage is close to zero for the smaller and largest firms (I-III and X decile). During busts these deciles show a larger increase of leverage with respect to central ones though for different sources: equity for smaller firms (due to lower or negative profits) and debt for largest firms (due to easier access to credit). Results on lagged relation are quantitatively weaker, but it is clear that for smaller firms leverage continues to increase also after a bust.

Section 4.4 shows the key innovative analysis of the paper: the role of size controlling for other possible confounding factors. ${ }^{10}$ Reassuringly, the results found among size classes (the U-shaped relations between leverage and busts driven by equity for the smaller firms and debt for the largest companies) remain. However, the cross-size heterogeneity due to equity goes down. Section 4.5 shows that the introduction of control variables decreases the cross-deciles differences in profits, which in turn drive equity dynamics.

Overall, these findings provide some implications about the relationships between leverage, economic growth and financial stability. Since smaller firms tend to increase leverage more than other companies during busts and show no lagged reduction, they are more likely to experience higher difficulties to invest or to access credit also during recoveries (e. g. Eramo et al., 2018). The evidence related to the leveraging phases is less clear-cut, but the dynamics of riskier firms is interesting, as

\footnotetext{
${ }^{10}$ The main findings related to other characteristics can be summarized as follows. Young firms display more volatile dynamics and, based on regression analysis, they tend to deleverage more with a lag; leverage of unprofitable and risky firms tends to grow also during booms; the influence of debt structure is mixed, as the cyclicality of leverage for firms relying only on short-term or bank funding is stronger than the others based on correlations, but similar using regressions.
} 
during expansions they tend to increase debt more than equity. Since these companies are more likely to suffer losses also during booms, lenders should ensure companies' shareholders increase equity in good times to avoid an excessive unbalancing of the financial structure.

The findings of this paper, based on a very long time span that includes three crises, can provide guidance also in the light of the recent Covid-19 pandemic. Although its economic and financial effects are difficult to forecast (as there is huge uncertainty about the evolution of the virus, the development of treatments, and the results of the extraordinary policy measures taken to support the economy), findings about firms' leverage dynamics observed in previous historical episodes can be useful to guide possible medium-term policy responses to the shock caused by the Covid-19 pandemic. Indeed, with respect to previous shocks, the combination of a (possible long-term) decline of firms' revenues and of a higher reliance on debit are likely to cause a larger increase of their leverage, as debt slows down less and losses are larger. While initial policy measures were fundamental to avoid widespread bankruptcies, a key issue to address in the medium term is the rebalancing of firms' debt with an increase of equity, especially in the case of smaller firms.

The main findings of this paper can be extended along two main related dimensions, which would also provide further information about the evolution during the pandemic crisis. ${ }^{11}$ First, including in the analysis also firms cash holdings. This development is related to a strand of literature that started after the financial crisis following the higher liquidity of firms (e.g. Acharya et al., 2007 and 2014; Sufi, 2009). As cash is negative debt, firms can rebalance their financial structure by reducing leverage and contemporaneously increasing liquidity; there is indeed some evidence that in Italy this happened after all the main busts (early 80s, early 90s and the more recent crises; see Appendix A5 for details and Dottori and Micucci, 2018).

The second extension would integrate the current evidence based on groups of companies and dummy variables by evaluating financial flexibility at firm level, similarly to DeAngelo et al. (2018). They study the deleveraging of US listed firms from their historical peak, finding that many companies coupled leverage reduction and increasing liquidity. The underlying motivation is that companies extensively increase their leverage when investment opportunities arise and rebuild their financial flexibility thereafter, unless they go bankrupt. Interestingly, they also report that less than half of these deleveraging processes occur during busts. This development would evaluate the existence of firm-leverage cycles, with a specific interest on deleveraging phases, which are more evident than leveraging ones on the base of the current analyses. Such study would complement the current results by assessing the relevance of both business cycles and firm-specific features for individual leverage dynamics. Its significance is supported by the preliminary evidence that also in Italy the change of leverage is very idiosyncratic: its median is around zero also during busts, as shown in Figure 4. ${ }^{12}$

\footnotetext{
${ }^{11}$ A third one, well beyond the scope of this paper, would be a more precise consideration of the supply side based also on historical time series of banks accounting data (supervisory reports) and lending relations (credit register).

${ }^{12}$ This extension requires a new dataset including firms with "long enough time span" data. DeAngelo et al. (2018) start with 14.000 firms, but then rely on less than 10.000 (with data for at least one year after their historical leverage peak) and 4.500 (which have five or more years of post-peak evidence).
} 


\section{References}

Acharya V. V., Almeida H., Campello M. (2007) "Is cash negative debt? A hedging perspective on corporate financial policies", Journal of Financial Intermediation 16, 515-554

Acharya V. V., Almeida H., Campello M. (2014), "Aggregate Risk and the Choice between Cash and Lines of Credit”, Journal of Finance, Vol. 58, pp. 2059-2116

Altissimo F., Marchetti D.J., Oneto G.P. (2000), “The Italian business cycle: coincident and leading indicators and some stylized facts", Bank of Italy Working Paper 377

Banca d'Italia (1981), Considerazioni finali del Governatore sul 1980, pag. 18

Banca d'Italia (1985), Considerazioni finali del Governatore sul 1984, pag. 18

Bank of Italy (2018), Annual Report for 2017

Begenau J., Salomao J. (2018), "Firm Financing over the Business Cycle", The Review of Financial Studies, vol. 32, no. 4, pp. 1235-1274

Covas F., Den Haan W. J. (2011), “The Cyclical Behavior of Debt and Equity Finance”, American Economic Review, vol. 101, no. 2, pp. 877-99

Crouzet N., Mehrotra N. R. (2018), "Small and Large Firms Over the Business Cycle”, mimeo

DeAngelo H., Gonçalves A. S., Stulz R. M. (2018), "Corporate Deleveraging and Financial Flexibility”, The Review of Financial Studies, v. 31, n. 8, pp. 3122-3174

Dinlersoz E., Kalemli-Ozcan S., Hyatt H., Penciakova V. (2018), "Leverage over the Life Cycle and Implications for Firm Growth and Shock Responsiveness", NBER Working Paper No. 25226

Dottori D., Micucci G. (2018), “Corporate liquidity in Italy and its increase in the long recession”, Bank of Italy Occasional Paper 420

Eramo G., Felici R., Finaldi Russo P., Signoretti F. M. (2018), "How slow is the recovery of loans to firms in Italy?", Bank of Italy Occasional Paper 469

Farre-Mensa J., Ljungqvist A. (2016), "Do Measures of Financial Constraints Measure Financial Constraints?", The Review of Financial Studies, v. 29, n. 8, pp. 271-308

Istat (2011), Rapporto annuale: La situazione del paese nel 2010

Frank, M. Z., Goyal, V. K. (2009), "Profits and Capital Structure", AFA 2009 San Francisco Meetings Paper

Karabounis M., Macnamara P., McCord R. (2014), “A Business Cycle Analysis of Debt and Equity Financing”, Economic Quarterly, vol. 100, n. 1, pp. 51-85

Jermann U., Quadrini V. (2012), "Macroeconomic effects of financial shocks", American Economic Review, vol. 102, pp. 238-271

Murray Z. F., Shen T. (2019), “Corporate Capital Structure Actions”, Journal of Banking and Finance, vol. 196, pp. 384-402

Sufi, A. (2009), "Bank lines of credit in corporate finance: An empirical analysis", Review of Financial Studies, Vol. 22, pp. 1057-1088

Varetto F. (2005), "Vent'anni di bilanci dell'industria italiana”, Global competition, vol. 1, pp. 27-32 


\section{Appendix}

Appendix A1 - The construction of the dataset starting from Centrale dei Bilanci

Centrale dei Bilanci (CeBi) includes detailed accounting information of Italian limited liability companies, starting from 1982. A more comprehensive database on balance sheet data of Italian companies is Cerved, which is however available only from 1993, thus without full information about the bust of the early Nineties.

The dataset used in this paper starts from CeBi data and includes two main filters. First, firms have to be active, meaning that their turnover and assets has to be strictly positive. The second filter is related to leverage, equal to the ratio between financial debt (bonds, bank loans and other loans, also from shareholders) and its sum with equity: the dataset includes only firms whose financial debt is clearly identified and whose leverage is not negative. ${ }^{13}$

The evolution over time of the number of firms by the main sectors of economic activity is reported in Figure A1. There are three main changes. First, an increase between 1993-4, which is possibly due to the introduction of Cerved. Second, another increase in 2002 (which is even larger in Cerved) and it is possibly due to the larger number of firms whose financial debts are clearly identified. Third, a decrease in 2013, which reflects a lower number of active firms and a possible lower reliance of the financial system on CeBi data. Nearly all firms belong to the manufacturing or the service sector.

Figure Al - Number of firms by economic activity in CeBi

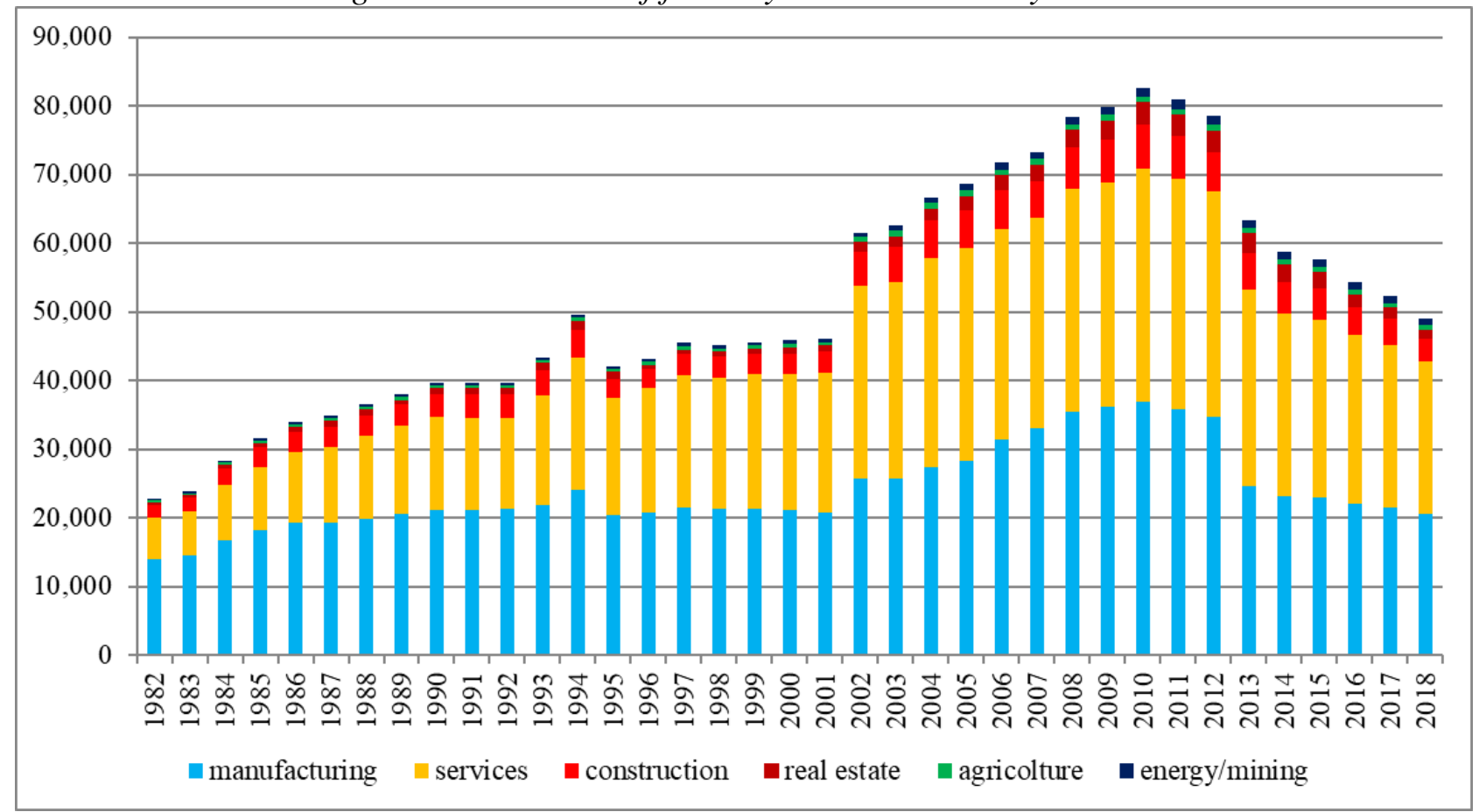

\footnotetext{
${ }^{13}$ A firm could have zero financial debt in CeBi and Cerved due to missing information. Such companies are included in the dataset with zero financial debt only in two cases: a) if they compile an ordinary balance sheet (Bilancio ordinario); b) if they report a simplified balance sheet (Bilancio semplificato) which includes information on trade and tributary debts. Finally, the condition on negative leverage implies that very distressed firms (those with negative equity whose absolute value is larger than debt) are excluded; on average these companies represent around 1.5 per cent of total assets.
} 
The representativeness of $\mathrm{CeBi}$ data can be assessed with a comparison with Cerved ones, starting from 1993 and ending in 2018; due to a large increase in the number of firms in both databases a more precise comparison should refer to 2002. Figure A2 shows that in these three years $\mathrm{CeBi}$ is highly representative of larger firms and (consequently) of the manufacturing and energy sectors: the coverage is nearly complete for medium and large firms, around 50 per cent for small companies, and negligible for micro firms. ${ }^{14}$

Figure A2 - Share of CeBi firms/Cerved firms (per cent)

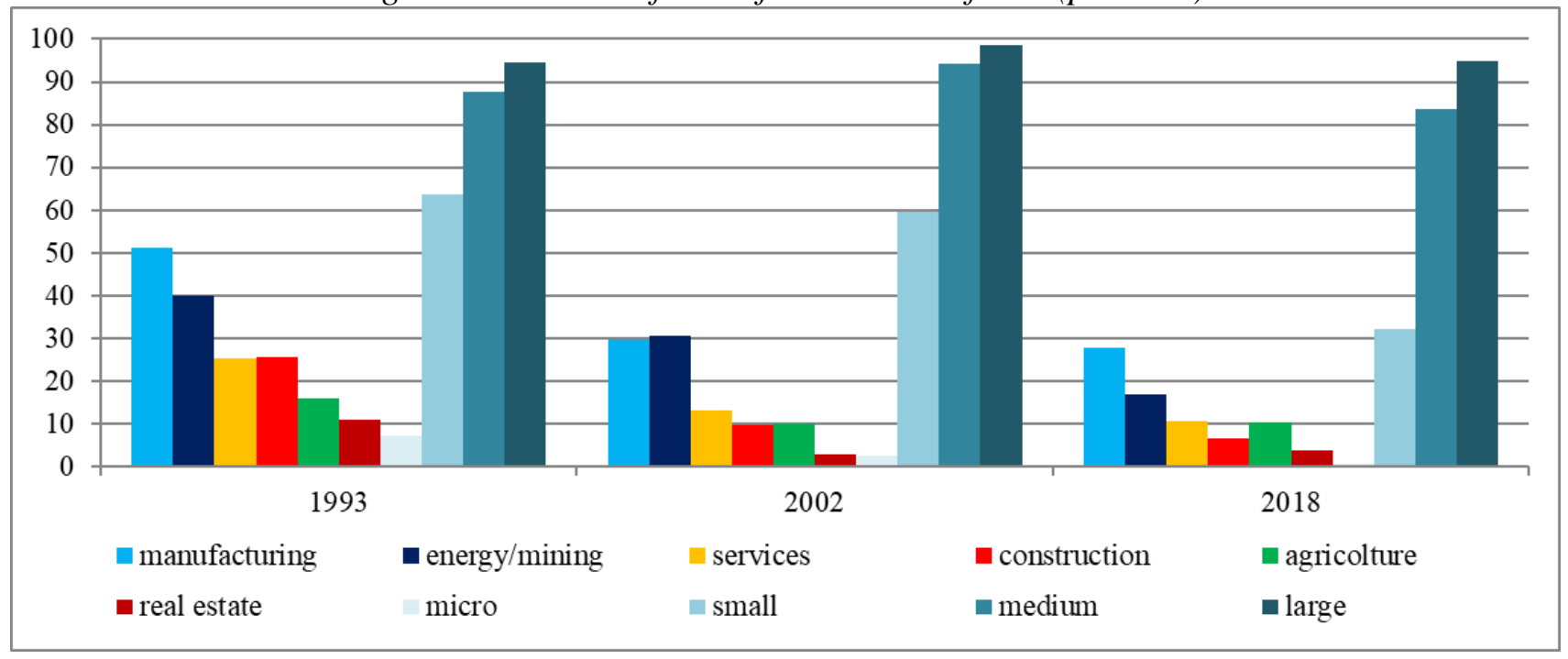

\section{Appendix A2 - Methodological issues and the contributions to leverage of debt and equity}

CeBi data can be used to derive the dynamics of leverage of Italian firms since 1982. However three issues has to be dealt with in order to obtain a cleaner picture: the effect of revaluation of assets on the value of equity, firms' demography, and inflation.

The first methodological issue is related to the definition of equity, which is composed by three items: (1) shareholders' funds, (2) a wide range of reserves (including past retained profits), (3) the current profits, net of dividends. The second item includes also "reserves from revaluation" which encompasses the value of assets revaluations allowed by law in specific years and therefore biases the amount of equity. ${ }^{15}$

Figure A3 shows the composition of equity, dividing between shareholders' funds, reserves from revaluation, other reserves, current year profits and dividends (the difference corresponds to retained earnings). Even if revaluation were allowed in many years, the share of the "reserves from revaluation" changed mainly in 1983, 1991, 2000, and 2008; in nearly all cases the amount roughly doubled in nominal term. Therefore a large part of the increase of equity in these years is only due to accounting procedures, especially in 1983; the change was proportionally small in 1991 and 2000 and somehow larger in 2008 .

\footnotetext{
${ }^{14}$ Size classes are based on European Commission definition of 2003. Due to the length of the time span and the high inflation in Italy before 1996, values of turnover and assets are deflated and calculated in 2003 euro.

${ }^{15}$ Assets revaluations were allowed in 1983, 1990, 1991, 2000, 2001, 2003, 2004, 2005, 2008, 2013, $2015,2016$.
} 
Figure A3 - Composition of equity (per cent)

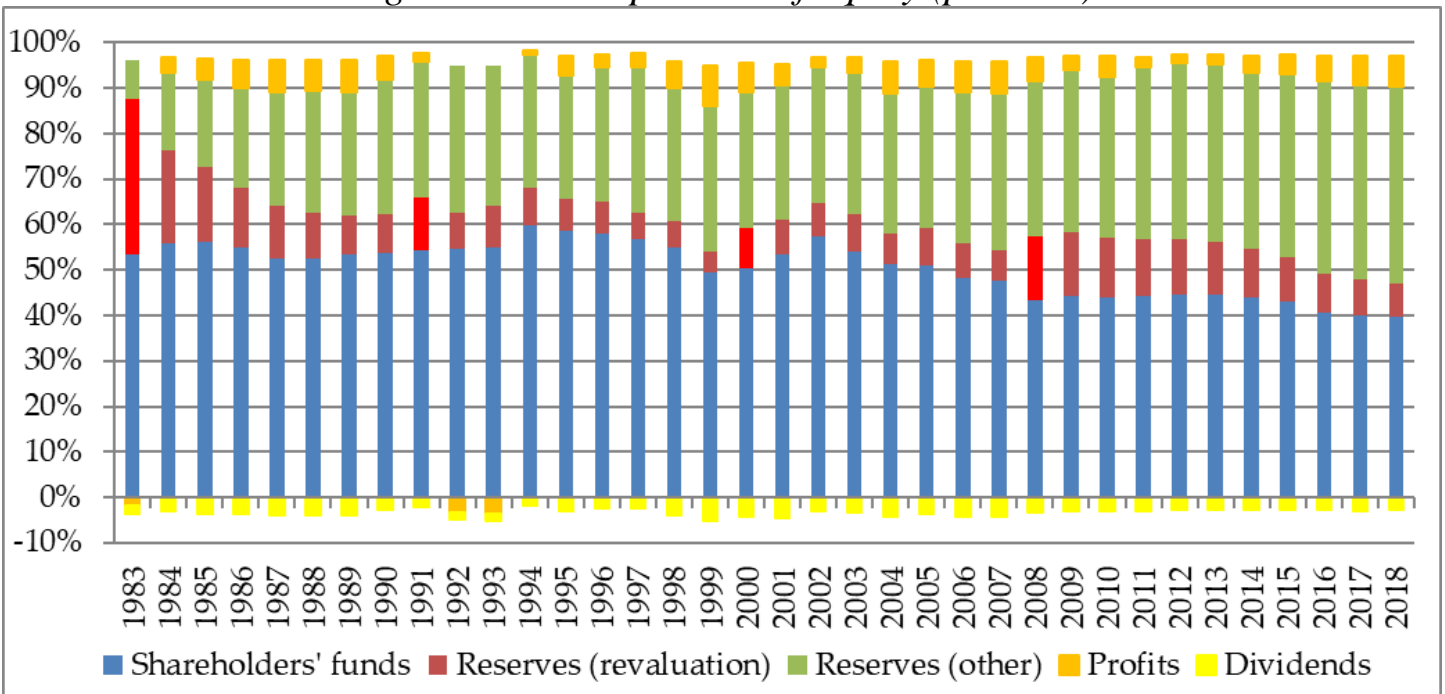

The second issue is related to the effects of the changes in sample size due to firms' entry (a firm enters when it has positive turnover and assets) and exit (a firm exits if it reports no balance sheet or it has zero turnover or zero total assets). In principle it would be interesting to study the role of demography, but due to the structural breaks reported in Appendix A1 such analysis would not be entirely reliable. Moreover, as the main variable of interest is the change of leverage at company level, firm data in two consecutive years are required by definition.

In this paper these two issues are tackled as follows. To avoid the distortion due to revaluations, I subtract the corresponding reserve from equity, thus deriving a cleaned measure of leverage. The second issue is avoided using of a 2-year closed sample. ${ }^{16}$

Figure A4.a shows the dynamics of the level of leverage between 1982 and 2018, displaying a decreasing trend of the undercapitalization of Italian companies. The benchmark time series is the green line (leverage for a 2-year closed sample excluding reserves from revaluation), which is basically equal to the black line (open sample without reserves), apart from 1991 and 2000 when the difference is 2 percentage points due to demography (cfr. infra).

The orange line (open sample with reserves) shows the bias due to assets revaluation: with respect to the black one, the level is lower but the dynamics are identical, with the exception of 1983/84, 1991, 2000, and 2008. The distortionary effects on leverage are clear. Without taking this issue into account (i. e. considering the orange line instead of the black one): a) following the massive reduction of leverage in 1983, 1984 would be wrongly considered as a year of increasing leverage, while leverage was still going down; b) in 1991 and 2000 the deleveraging would be overestimated; c) 2008 would wrongly be classified as a deleveraging year.

Figure A4.b directly compares the changes of leverage for the open and closed sample. The contribution of demography to the changes of leverage between $t$ and $t+1$ is decomposed in three parts: a) survivors (closed sample of firms living in both years), b) new firms (living in $t+1$ only); c) exited firms (living in $t$ only).

\footnotetext{
${ }^{16}$ The share of firms not belonging to a 2-year closed sample is on average equal to 12 per cent, but in some years there are huge changes in the number of firms $(1984,1993,1994$ and 2002) and the share is above 20 per cent. The excluded firms represent on average a smaller share in terms of the sum of debt and equity (around 7 per cent).
} 
More precisely, the decomposition is the following: define $\mathrm{L}$ as the leverage of the closed sample and Lc as the leverage of the open sample, then

(1) Total change of leverage $=\mathrm{L}_{\mathrm{t}}-\mathrm{L}_{\mathrm{t}-1}$

(2a) Survivor $=\mathrm{Lc}_{\mathrm{t}}-\mathrm{Lc}_{\mathrm{t}-1}$

(2b) Exit $=\mathrm{Lc}_{\mathrm{t}-1}-\mathrm{L}_{\mathrm{t}-1}$

(2c) Entry $=\mathrm{L}_{\mathrm{t}}-\mathrm{Lc}_{\mathrm{t}}$

and $(1)=(2 a)+(2 b)+(2 c)$

The differences between the two series are relatively small and the sign of the change is mostly the same, apart from 1991 and 2000. ${ }^{17}$ In general, new firms increase leverage (as they have very low or negative equity) while exiting firms reduces it (as more leveraged firms are more likely to go out of business).

\section{Figure A4 - Leverage and demography \\ a) levels (per cent)}

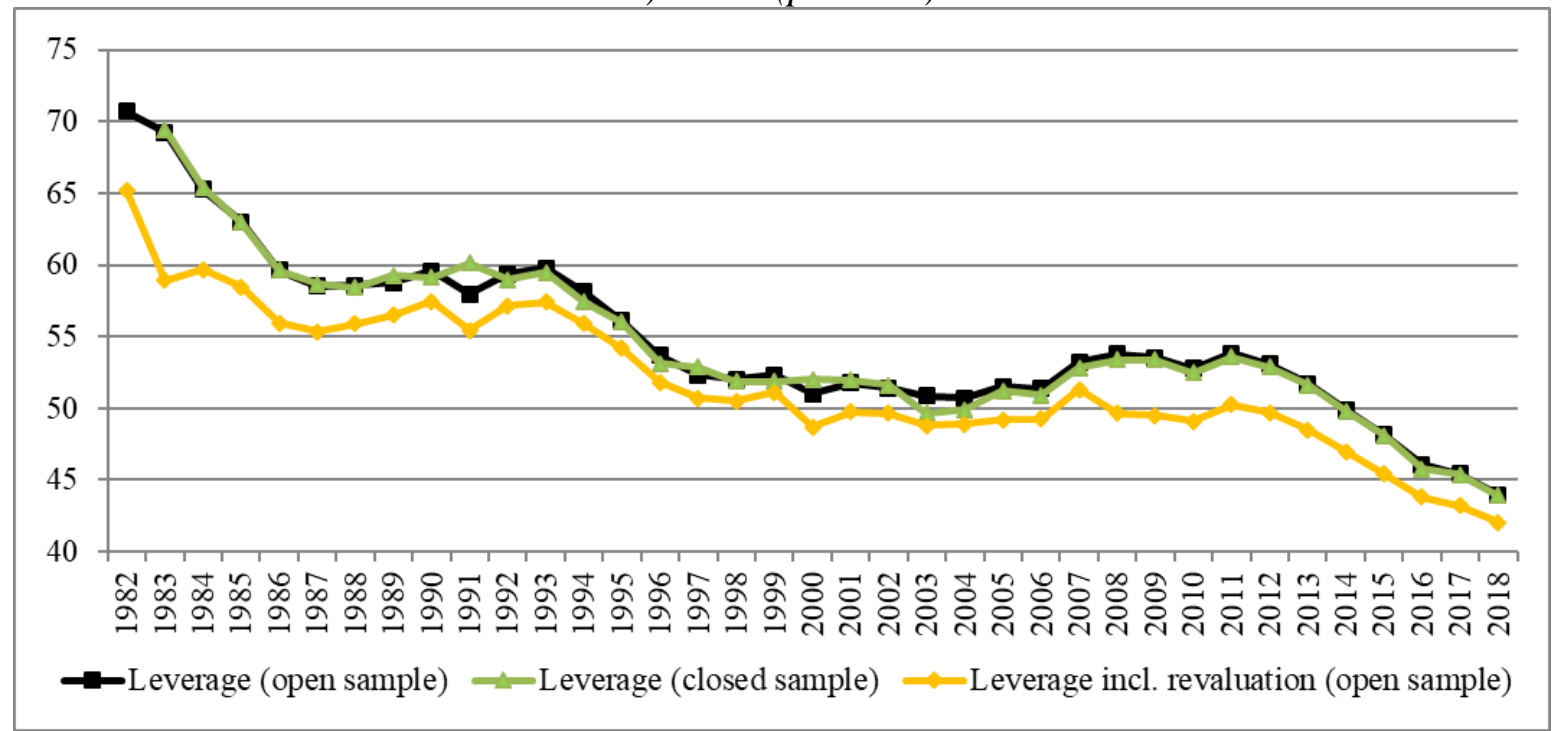

b) changes (percentage points)

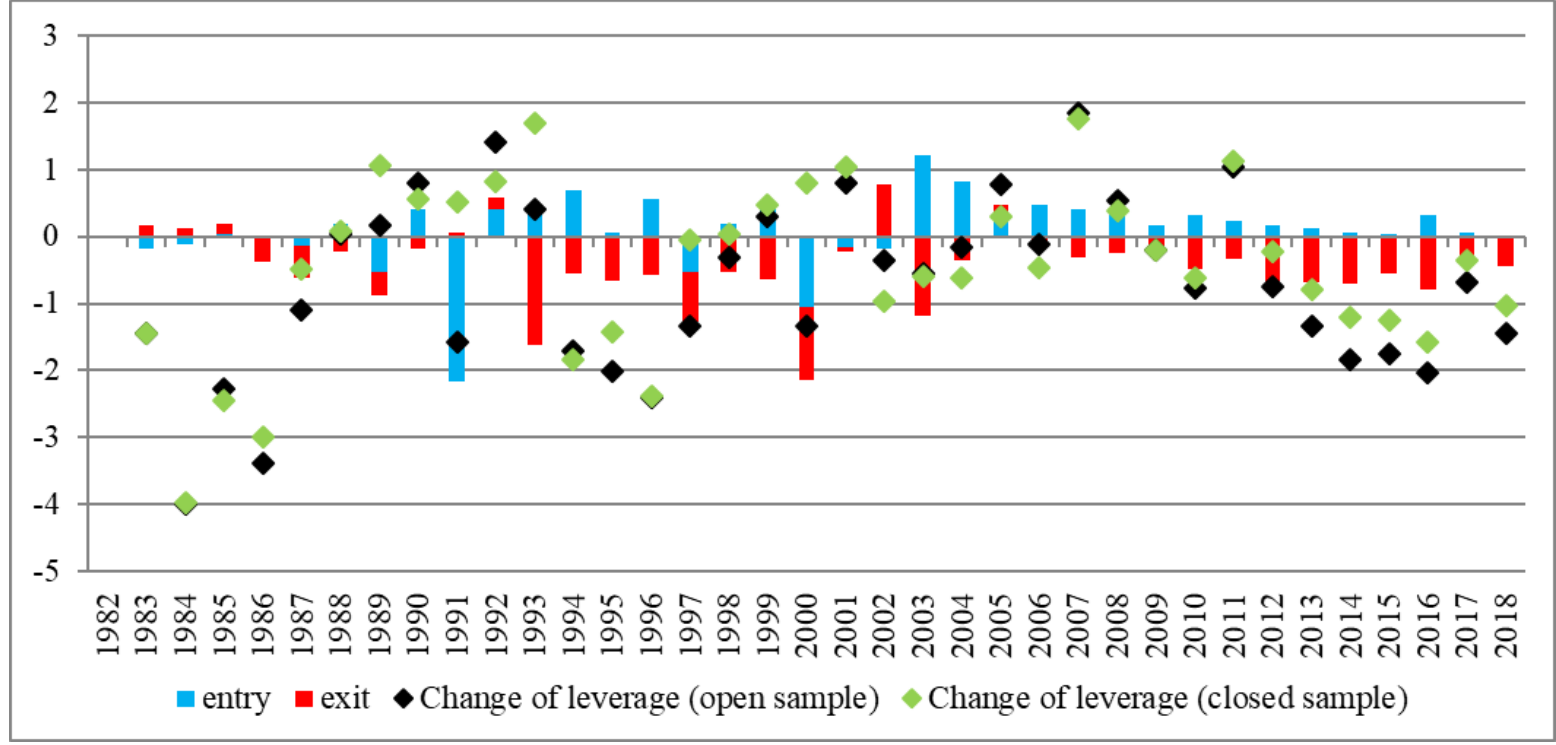

${ }^{17}$ In both years the changes are driven by the entry of a single very large firm with a very low level of leverage. 
The third issue is inflation. Even if is not a relevant issue for leverage (as it is a ratio, price changes affect equally both the numerator and the denominator so that their effects cancel out), inflation can affect the nominal dynamics of debt and equity. To overcome this issue, the analysis of the two components of the ratio is based on their respective contributions to the change of leverage, derived as follows. Define D as the financial debt of the firms and E as their equity, than the change of leverage between $t$ and $t+1$ can be rewritten as follows

$$
\begin{aligned}
& \Delta L e v_{t}=\frac{\mathrm{D}_{t}}{\mathrm{D}_{t}+E_{t}}-\frac{\mathrm{D}_{t-1}}{\mathrm{D}_{t-1}+E_{t-1}}=\frac{\mathrm{D}_{t} *\left(\mathrm{D}_{t-1}+E_{t-1}\right)-\mathrm{D}_{t-1} *\left(\mathrm{D}_{t}+E_{t}\right)}{\left(\mathrm{D}_{t}+E_{t}\right) *\left(\mathrm{D}_{t-1}+E_{t-1}\right)}=\frac{\mathrm{D}_{t} * \mathrm{E}_{t-1}-\mathrm{D}_{t-1} * \mathrm{E}_{t}+\mathrm{E}_{t} \mathrm{D}_{t}-\mathrm{E}_{t} \mathrm{D}_{t}}{\left(\mathrm{D}_{t}+E_{t}\right) *\left(\mathrm{D}_{t-1}+E_{t-1}\right)}= \\
& \frac{E_{t} *\left(D_{t}-D_{t-1}\right)-D_{t} *\left(E_{t}-E_{t-1}\right)}{\left(\mathrm{D}_{t}+E_{t}\right) *\left(\mathrm{D}_{t-1}+E_{t-1}\right)}
\end{aligned}
$$

and decomposed in two parts:

$$
\begin{aligned}
& \text { a. contribution of debt }=\frac{\mathrm{E}_{t} * \Delta \mathrm{D}_{t}}{\left(\mathrm{D}_{t}+E_{t}\right) *\left(\mathrm{D}_{t-1}+E_{t-1}\right)} \\
& \text { b. contribution of equity }=-\frac{\mathrm{D}_{t} * \Delta \mathrm{E}_{t}}{\left(\mathrm{D}_{t}+E_{t}\right) *\left(\mathrm{D}_{t-1}+E_{t-1}\right)}
\end{aligned}
$$

The key advantage of this decomposition is the possibility to disentangle precisely the relative contribution of debt and equity. The yearly change of debt (equity) is weighted by the end-period level of equity (debt) at the numerator, while the denominator is common for both terms and it is always positive. Hence the sign of each contribution to leverage is due to the yearly change of the respective variable $\Delta \mathrm{D}_{t}$ or $\Delta \mathrm{E}_{t}$, while the relative importance is weighted by the final level of the complementary variable $\mathrm{E}_{t}$ or $\mathrm{D}_{t}$. This advantage of this methodology has its flip of the coin, because the relative contributions are not independent from the initial and final levels of the two variables, which are included in the denominator.

There are two possible alternative measures: the percentage change of debt or equity deflated by the inflation rate or their changes standardized by total assets. The proposed decomposition copes with their shortcomings. The first alternative has two main concerns: it may have more outliers and inflation could not represent a precise correction for changes of balance sheet variables. The two main issues of the second alternative are the distortions due to the revaluation of assets (discussed before) and the fact that similarly to the proposed decomposition the denominator is influenced by the variables under analysis (total assets is the sum of equity, financial debt and other non-financial debt).

The possible concerns about the proposed decomposition are dispelled by the fact that all the alternatives under exam are highly correlated (Fig. A5). This evidence is explained by the fact that all methodologies scale with different weights the same variables, i. e. the change of debt $\Delta \mathrm{D}_{t}$ or of equity $\Delta \mathrm{E}_{t}$. This finding supports the decision to rely on a precise decomposition of leverage, which has the key advantage to disentangle the relative contribution of its two components. 
Figure A5 - Contribution of debt and equity - alternative options (per cent) a) debt

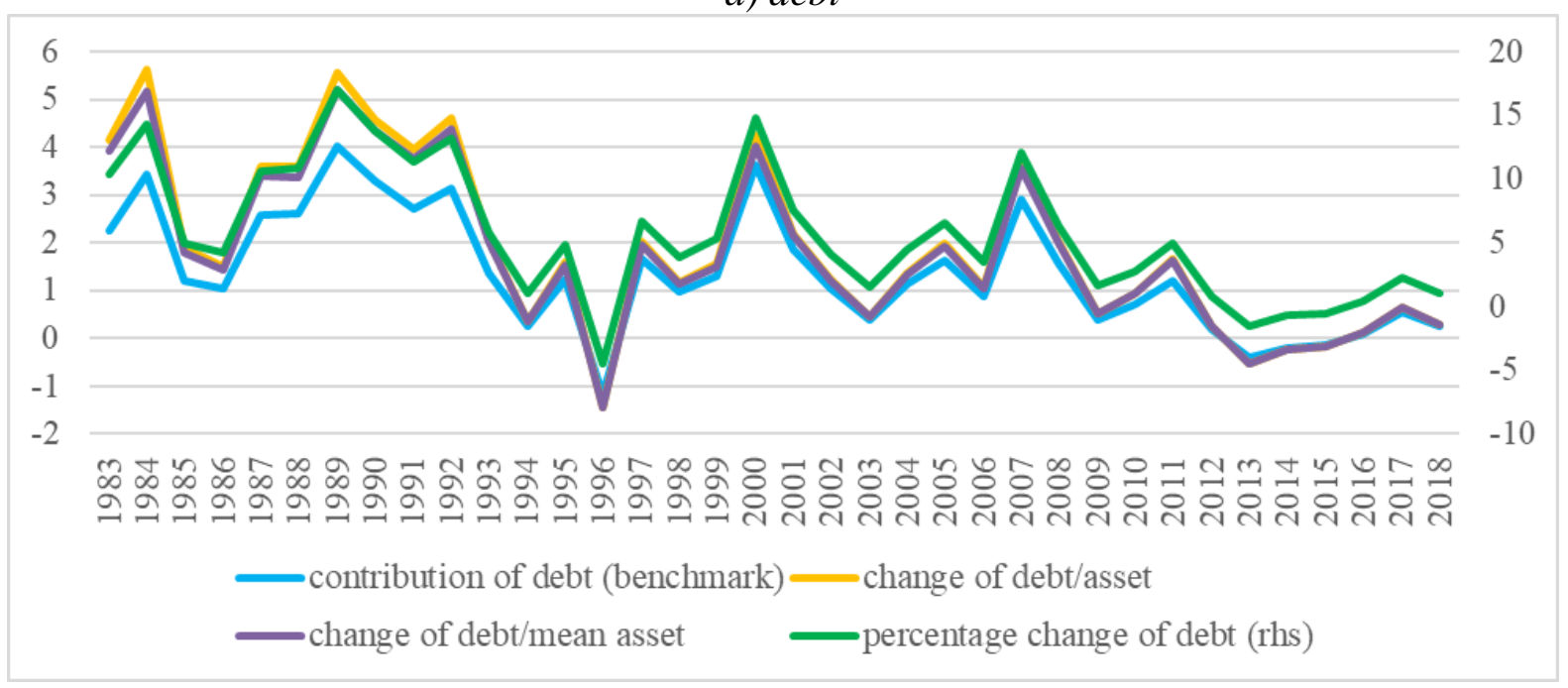

b) equity

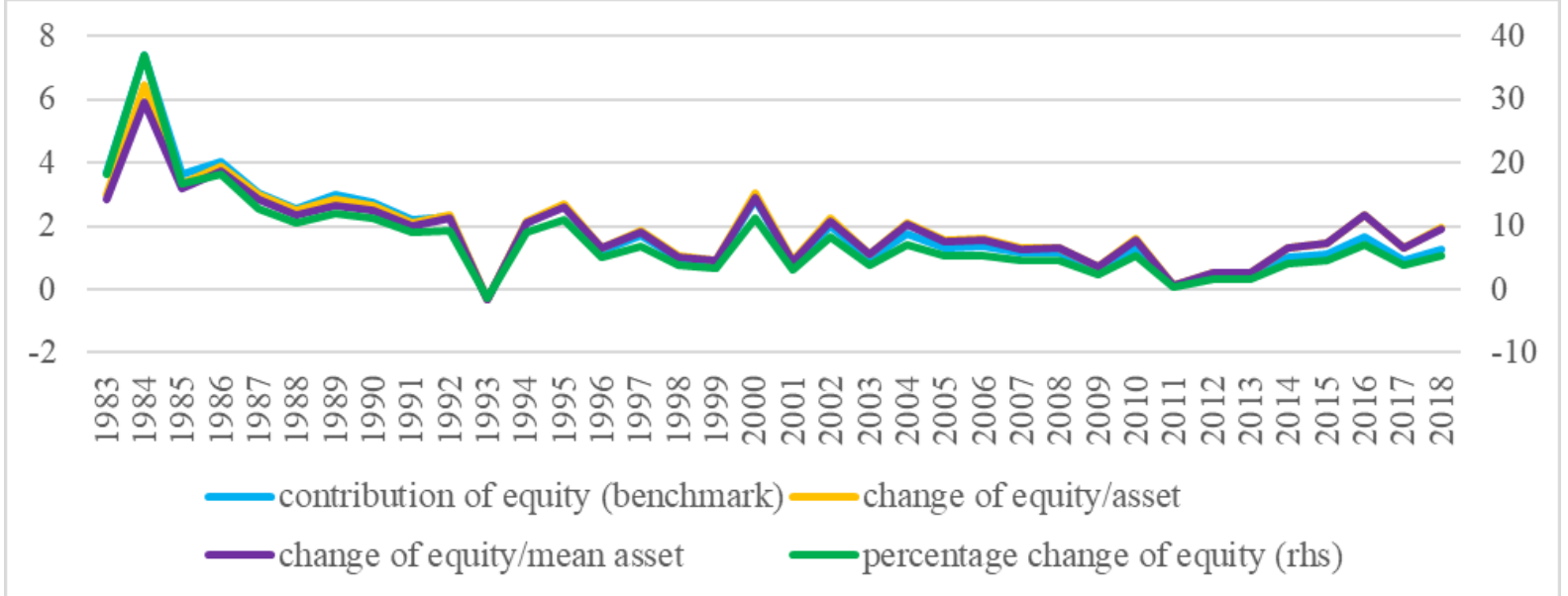

Note: The contribution of debt and equity (blue lines) is calculated as in formula (a) and (b), respectively. The numerator of the other three options is $\Delta D(t)$ in panel a and $\Delta E(t)$ in panel b, while the denominators are the level of assets in $t$ (yellow lines), the mean level of assets in $t$ and $t-1$ (purple lines) and the level of debt or equity in $t-1$ (green lines).

\section{Appendix A3 - Business cycles in Italy}

The definition of expansionary (trough to peak) and contractionary (peak to trough) periods in Italy is based on the turning points identified up to the beginning of 2011 by Istat (2011; fig, A6.a) and updated up to the beginning of 2018 by Bank of Italy (2018), following the methodological approach of the National Bureau of Economic Research (NBER). ${ }^{18}$ More specifically, the analysis of cyclical turning points in Italy is based on the performance of 6 variables (the ratio of overtime hours to total hours worked in large firms, the industrial production index, the rail transport of goods, the value added of market services, plant and machinery investment, and the imports of goods) summarized by a composite coincident indicator (Altissimo et al., 2000).

\footnotetext{
${ }^{18}$ According to NBER a recession "is a significant decline in economic activity spread across the economy, lasting more than a few months, normally visible in real GDP, real income, employment, industrial production, and wholesale-retail sales" and it is not defined "in terms of two consecutive quarters of decline in real GDP" (https://www.nber.org/cycles.html). It should be noted that the evaluation of the precise turning points is somehow discretionary, the reason why the NBER's Business Cycle Dating Committee exists.
} 
It is interesting to note that in many cases quarterly GDP growth rates represent a very good proxy to identify turning points: a peak usually corresponds to the last quarter preceding a non-negligible negative growth in the following two consecutive quarters, while a trough corresponds to the last quarter of these periods of negative growth (fig. A6.b).

Figure A6 - Business cycles in Italy

a) Istat (2011) composite indicator of Italian economy (1995=100)

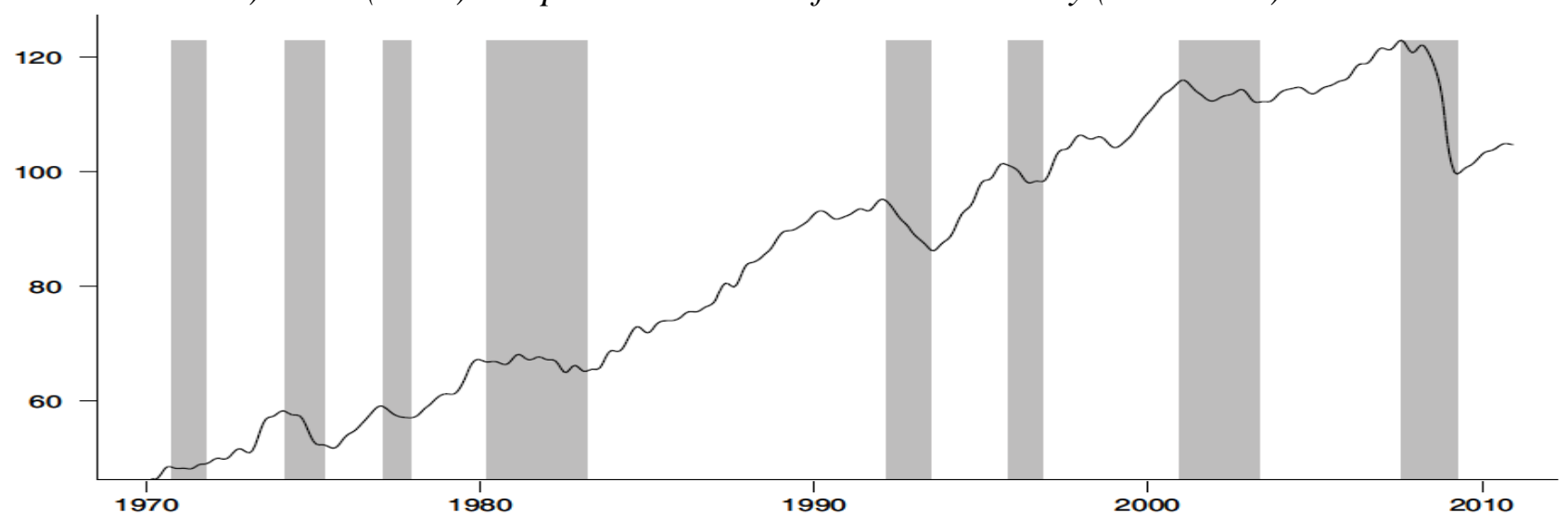

b) quarterly real GDP (1982-2018)

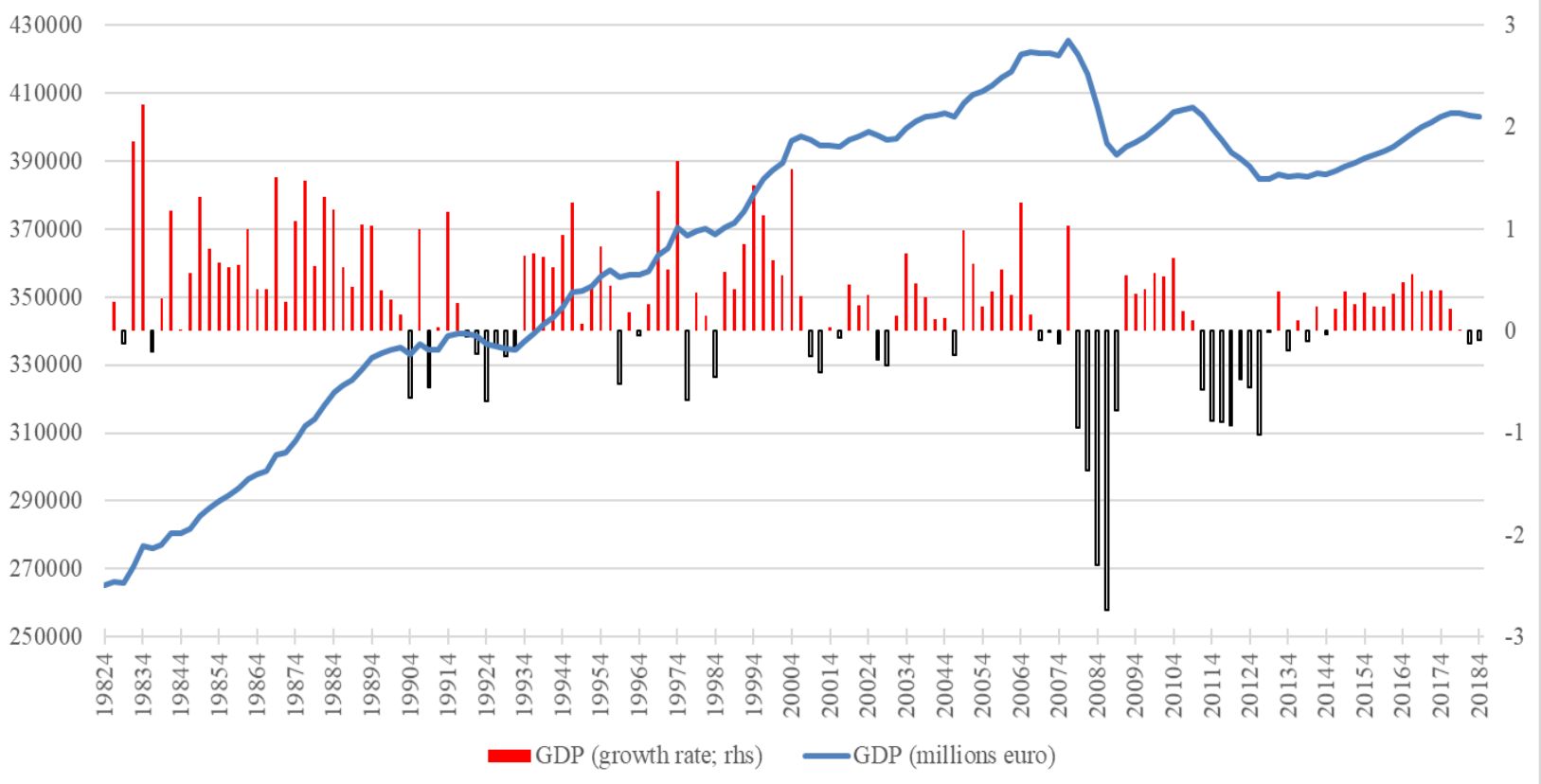

Table A1 reports the turning points according to the two official sources or using the GDP growth rate as described before; the slight discrepancies are possibly due to revisions of macroeconomic data or to discretionary evaluation of the precise turning points. As the frequency of firm-level data is yearly, I align the monthly/quarterly macroeconomic information as follows. In nearly all cases the contractionary years are clearly identified because the slumps last for at least three quarters (1992, 1993, 1996, 2001, 2002, 2008, 2012), while in four cases the identification is less straightforward (2003, 2009, 2011, 2013). I consider all these years as contractionary as in 2003, 2009 and 2013 the economic recovery remained weak compared to the previous decline and in 2011 a large and sudden recession started in the second half of the year. 
Table A1 - Alternative definitions of business cycles in Italy

\begin{tabular}{|c|c|c|c|c|c|}
\hline \multicolumn{2}{|c|}{ Istat, 2011 (1945-2010) } & \multicolumn{2}{|c|}{ Bank of Italy, 2018 (1971-2018Q1) } & \multicolumn{2}{|c|}{ Negative GDP growth (1982-2018) } \\
\hline Through & Peak & Through & Peak & Through & Peak \\
\hline Dec-77 & Mar-80 & 1977Q4 & 1980Q1 & - & - \\
\hline Mar-83 & Mar-92 & 1983Q1 & 1992Q1 & - & 1992Q1 \\
\hline Jul-93 & Nov-95 & $1993 Q 3$ & 1996Q1 & 199303 & 1996Q1 \\
\hline Nov-96 & Dec-00 & 1996Q4 & 2001Q1 & 1996Q4 & 2001Q1 \\
\hline May-03 & Aug-07 & $2003 Q 2$ & 2008Q1 & $2003 Q 2$ & 2008Q1* \\
\hline Apr-09 & - & $2009 Q 2$ & 2011Q2 & $2009 Q 2$ & 2011Q2 \\
\hline - & - & 2013Q1 & - & $2013 Q 2 * *$ & - \\
\hline
\end{tabular}

Note: *quarterly GDP growth was only slightly negative from 2007Q2 to 2007Q4 and therefore this time span is not considered as contractionary; ** quarterly GDP decreased markedly in 2013Q1 and marginally went down in $2013 \mathrm{Q} 2$.

Summing up, after a 3-year long contractionary period between 1980 and 1982, there have been two deeper contractionary episodes (1992-93 and the double-dip recession in 2008-09/2011-13) and two other slumps (1996 and 2001-03).

In order to evaluate the reliability of this yearly qualitative identification, I compare it with a quantitative one based on quarterly GDP growth rates (in order to use data as similar as possible to those employed in the official identification of turning points). One of the simplest alternatives is the average of the four quarterly growth rates, shown in Fig. A7 (results are similar using the median). The growth rates of the 11 contractionary years are either negative (7) or very close to zero (4).

This measure is not perfect, as 4 years (out of 23) that are classified as expansionary also have negative or very low growth rates: 1990 (due to a very negative fourth quarter), 1998 (which includes two quarter with very negative growth), 2007 (which includes three quarters with slightly negative growth), and 2014 (which is a year of stagnation). In any case the classification of all these four years is somehow unclear, as there is no steady positive growth of the composite indicator or of the quarterly GDP (cfr. Fig. A6).

Figure A7 - Yearly means of quarterly GDP growth rates

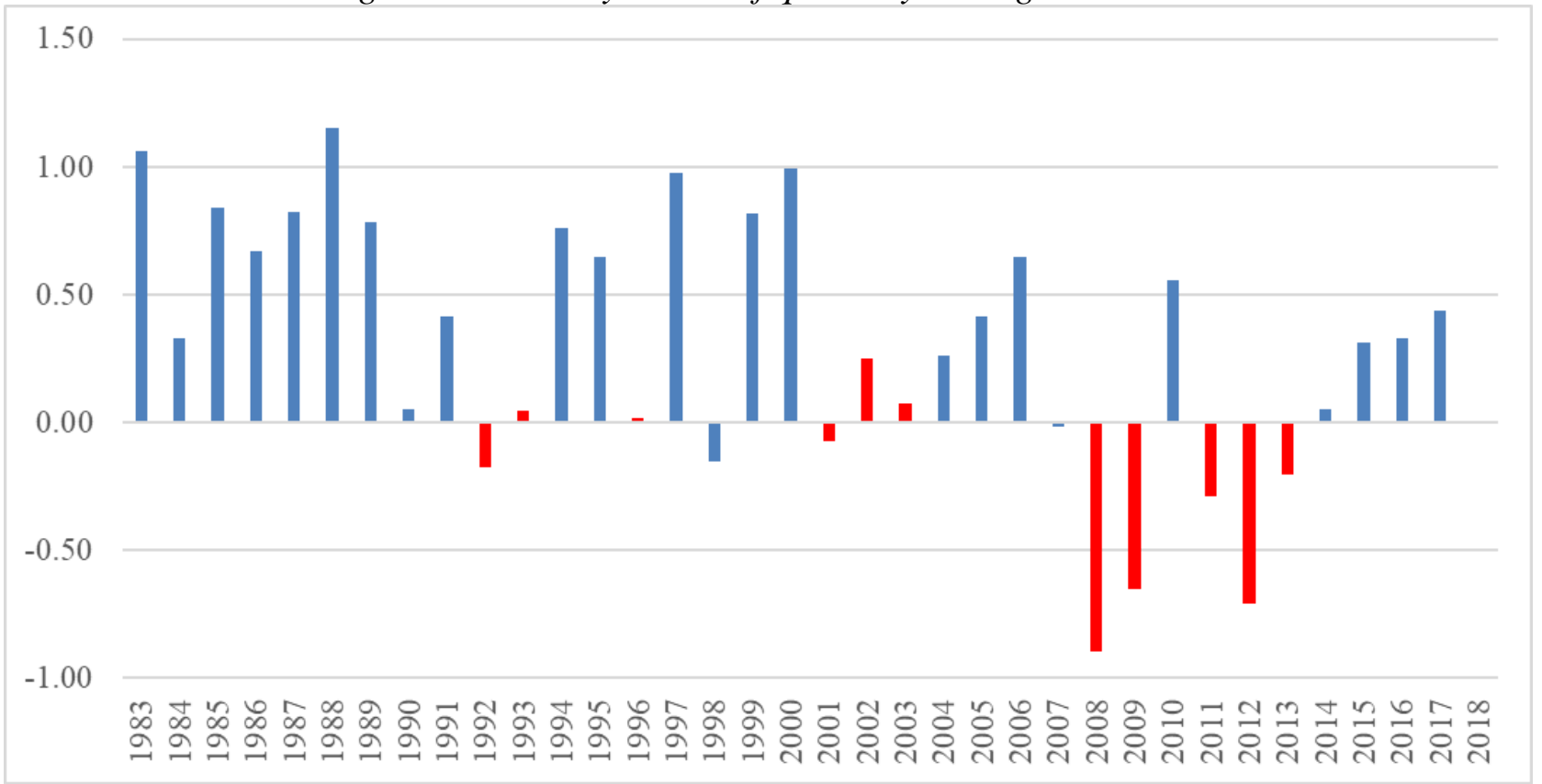

Note: Red (blue) histograms identifies busts (booms). 


\section{Appendix A4 - Dynamics of leverage, debt and equity over time by firm characteristics}

The previous literature on the relation between leverage and the business cycle highlighted the role of few very large firms when aggregate dynamics are evaluated. Figure A8 confirms this finding for Italy: the aggregate level of leverage is influenced by the top centile of the size distribution by assets (around 200-700 companies depending on the year). Leverage decreased at the beginning of the 80s, the 90s and the 2010s, and the role of the largest firms was particularly relevant in the first two episodes.

In Italy the aggregate leverage dynamics is deeply influenced by very large companies also because their financial structure was entirely different from other firms at the beginning of the time span under analysis. Large companies were highly leveraged at the beginning of the 80s (Banca d'Italia, 1981), strengthened their financial structure in the first years of that decade (Banca d'Italia, 1985) and also in the second part of the Nineties (Varetto, 2005) so that their leverage nearly halved between 1982 and 1997. Later on the differences with other firms decreased as the largest companies started to leverage up, so that in 2013 the differences among size classes were negligible and during the last deleveraging episode there were basically no differences.

Figure A8 - Leverage and size - open sample, excluding assets revaluations (per cent)

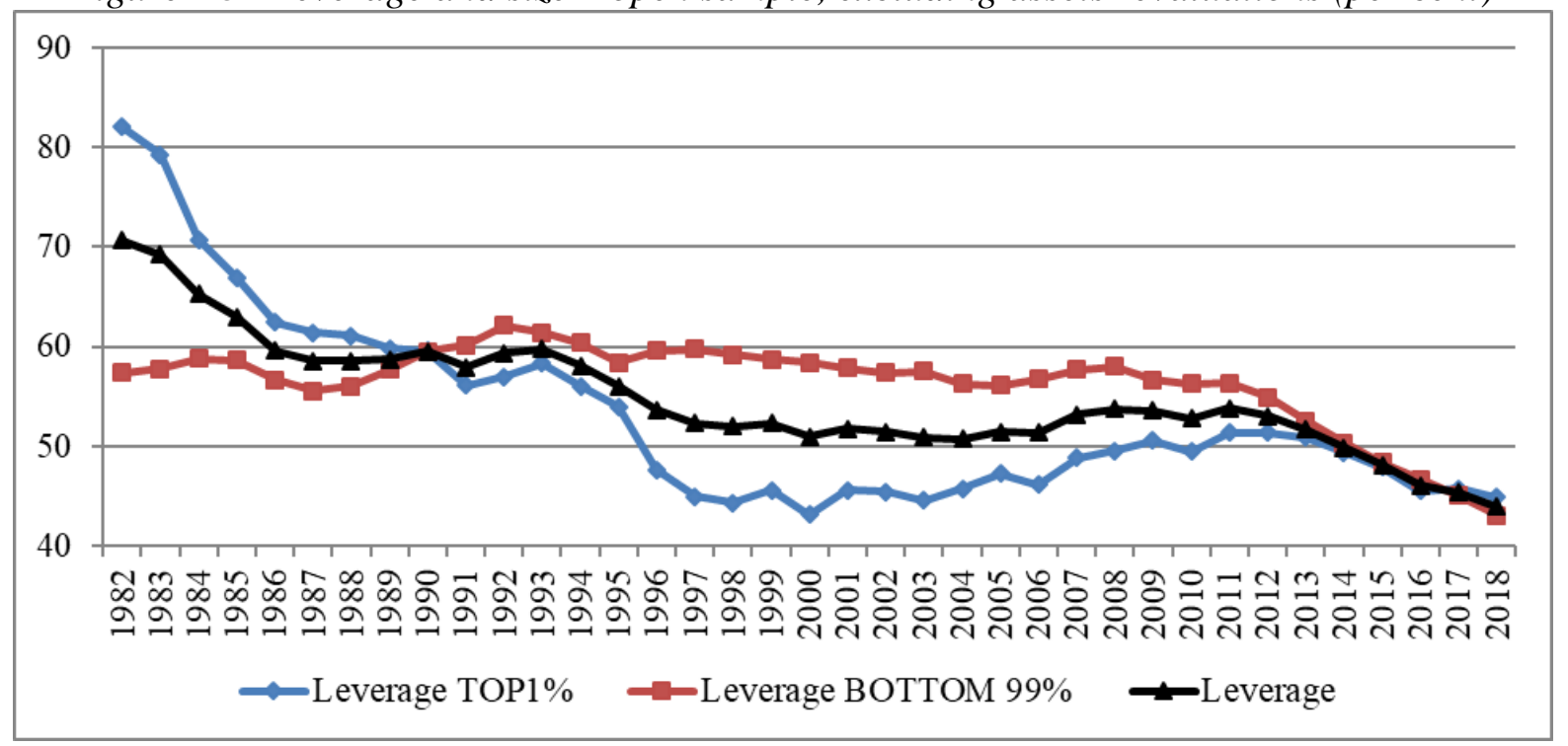

Figures A9.a and A9.b show that the aggregate change of leverage is strongly influenced by the top 1 per cent and basically determined by the $\mathrm{X}$ decile, mainly because these companies (around 2.000-7.000, depending on the year) represent 75 per cent of the sum of debt and equity of the overall sample. There are relevant differences between the $\mathrm{X}$ decile and all other firms (Figure A9.c): for companies belonging to the I-IX decile, the deleveraging after the two main busts (1983-1987 and 1994-96) is less clear-cut and the following changes of leverage are smaller and mostly negative. The I decile exhibits a peculiar behaviour (Figure A9.d): the change of leverage is negative in almost all years, because the usual contributions are reversed: financial debt decreases and compensates the effect of lower equity, which increases leverage. 
Figure A9 - Change of leverage and contribution of debt and equity (percentage points) a) Top 1 per cent (by assets)

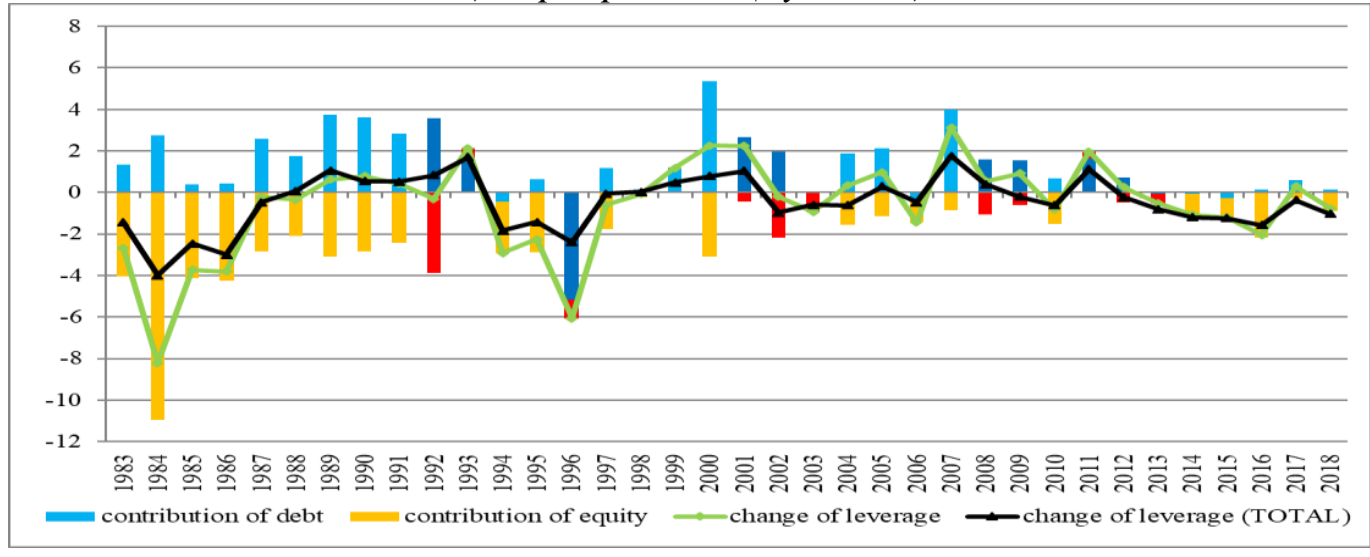

b) $X$ decile (by assets)

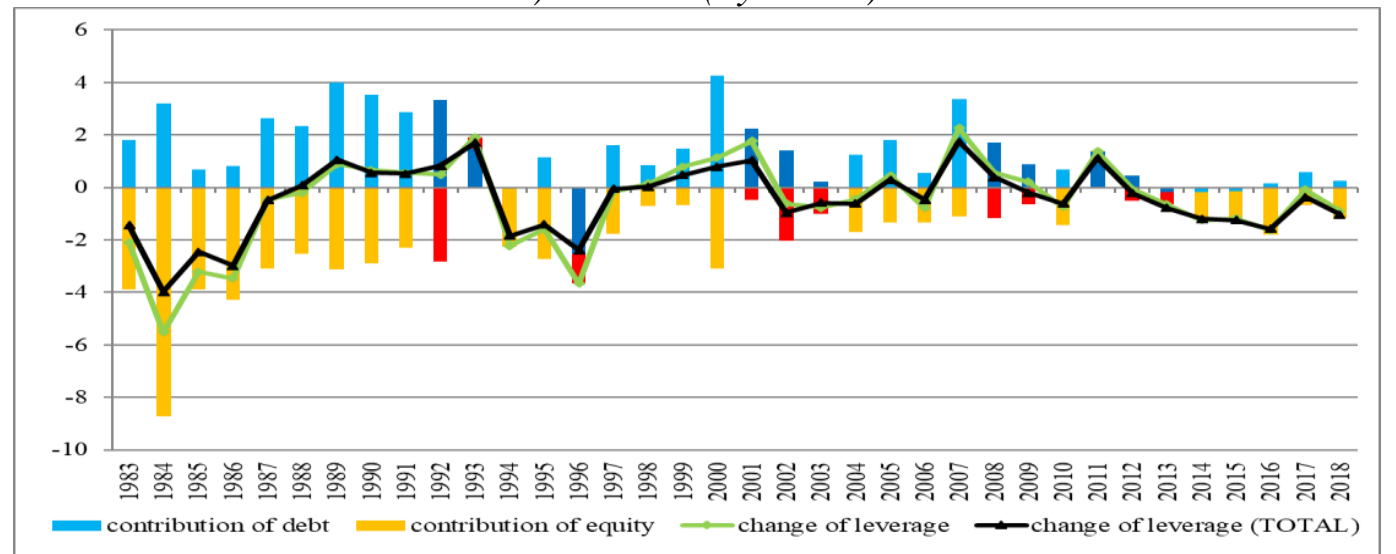

c) I-IX decile (by assets)

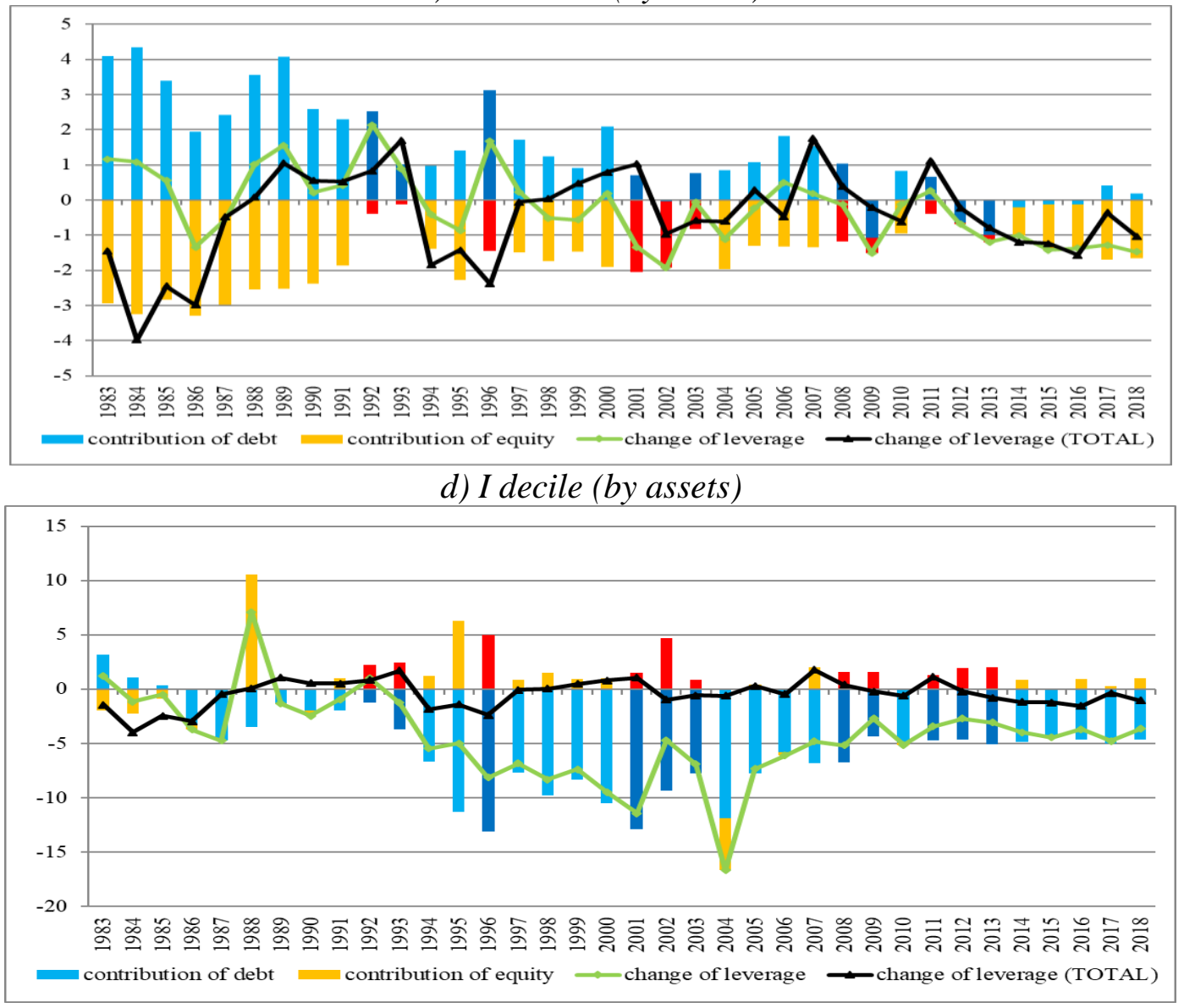


The heterogeneity of the relation between leverage and the business cycle depend also on other firms' characteristics that are likely to affect differently the reaction of equity or debt during busts. This issue is quite relevant, because size could proxy for other variables. Indeed, in the sample of Italian firms size is correlated positively with age and negatively with reliance on short-term and bank debt, although the correlations are below 0.20 (Table A2).

Table A2 - Correlation matrix - firm characteristics

\begin{tabular}{|c|c|c|c|c|c|c|}
\hline & Size & Age & Risk & Ebitda $>0$ & $\begin{array}{c}\text { Short } \\
\text { debt }=100 \%\end{array}$ & $\begin{array}{c}\text { Bank } \\
\text { debt }=100 \%\end{array}$ \\
\hline Size & 1 & & & & & \\
\hline Age & 0.18 & 1 & & & & \\
\hline Risk & -0.04 & -0.13 & 1 & & & \\
\hline Ebitda $>0$ & 0.05 & 0.02 & -0.28 & 1 & & \\
\hline Short debt=100\% & -0.16 & -0.08 & 0.01 & -0.05 & 1 & \\
\hline Bank debt $=100 \%$ & -0.14 & 0.01 & 0.00 & 0.05 & 0.24 & 1 \\
\hline
\end{tabular}

Figure A10 shows the dynamics for three classes of firms: young (first quartile by age), median (second and third quartile), and old (forth quartile). In theory, the relation between age and leverage is ambiguous: access to credit for younger firms is more difficult but they also usually have a higher probability of reporting negative earnings; access to credit for older firms is easier, but they also rely more on (usually) higher and more stable profits. The descriptive analysis shows clear differences: young firms are characterized by wider and more erratic changes, mostly related to the contribution of equity; the dynamics of the other two classes are similar, even if the contribution of debt and equity is somehow more stable for old firms, especially during recessions.

The previous findings imply that for some (younger, possibly smaller) firms leverage dynamics depend on equity; profitability is another variable of interest as it indirectly affects equity through losses. Figure A11 shows the dynamics of leverage for firms with negative EBITDA, which are likely to have also negative profits. The share of such companies is around 7-10 per cent before 2002 and 12-18 per cent after, as the number of smaller and less profitable firms increased. Their leverage tends to grow, especially during recessions, as usually debt increases (by small amount) while equity decreases.

Another relevant factor of leverage dynamics is riskiness, as measured by Cerved Z-score. Figure A12 shows that the changes of leverage of sound firms tend to be similar but less pronounced than the aggregate, as the contribution of equity is more stable; instead the leverage of risky ones usually increases, as equity usually decreases and drives the dynamics of leverage.

A final feature that is likely to affect leverage dynamics is the structure of financial debt. I distinguish between firms whose debt is only short term (around 25 per cent up to 2005 and 20 per cent thereafter) and those with bank debt only (around 45 per cent before 1992 and 30 per cent thereafter), as these two groups should respond more to negative business cycles, especially in the debt component. Figure A13 shows that companies relying only on short term funding usually have negative changes of leverage, especially during recessions when the contribution of debt is smaller or negative. Firms relying only on bank funding have similar dynamics, especially in the last twenty years. 
Figure A10 - Change of leverage and contribution of debt and equity a) Young firms (first quartile)

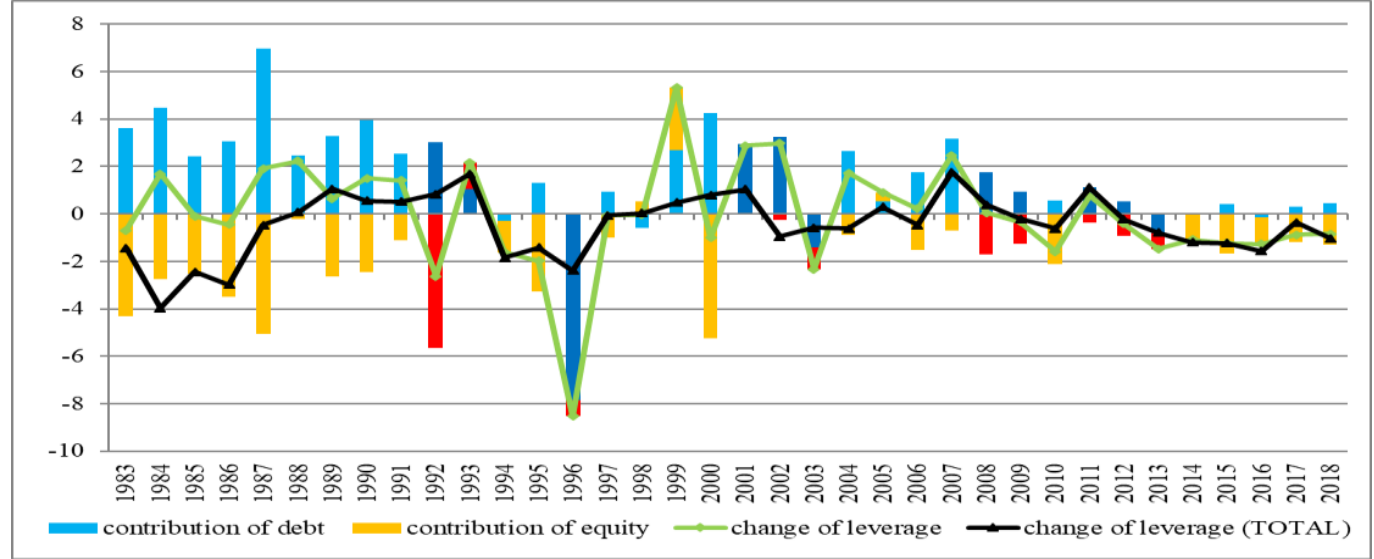

b) Median firms (second\&third quartile)

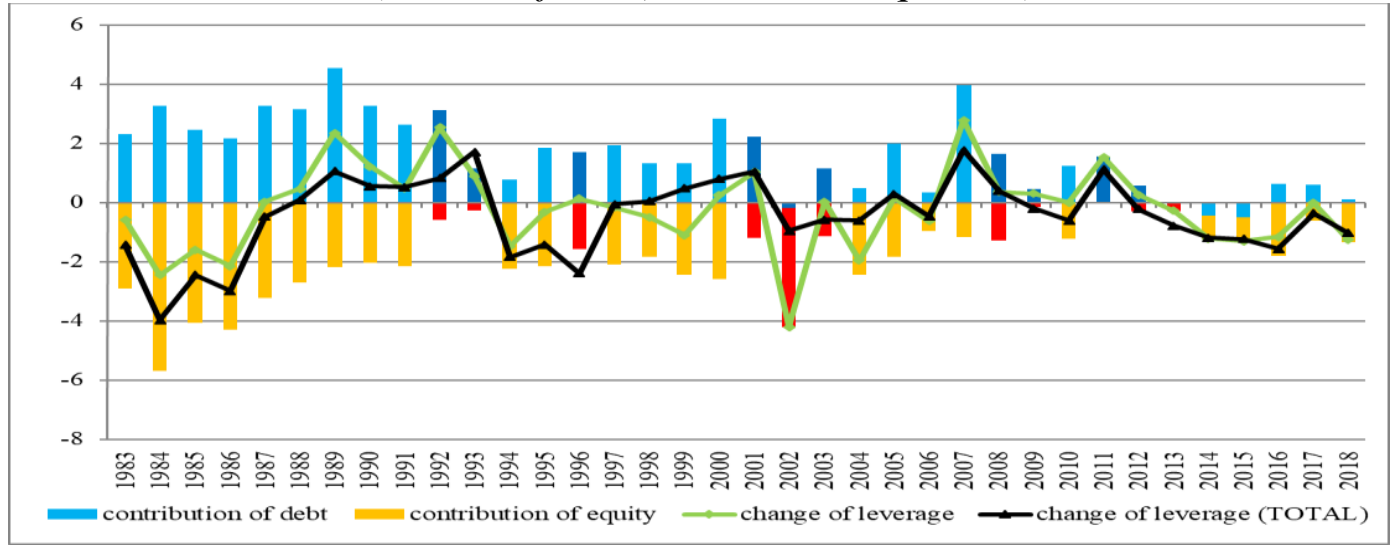

c) Old firms (fourth quartile)

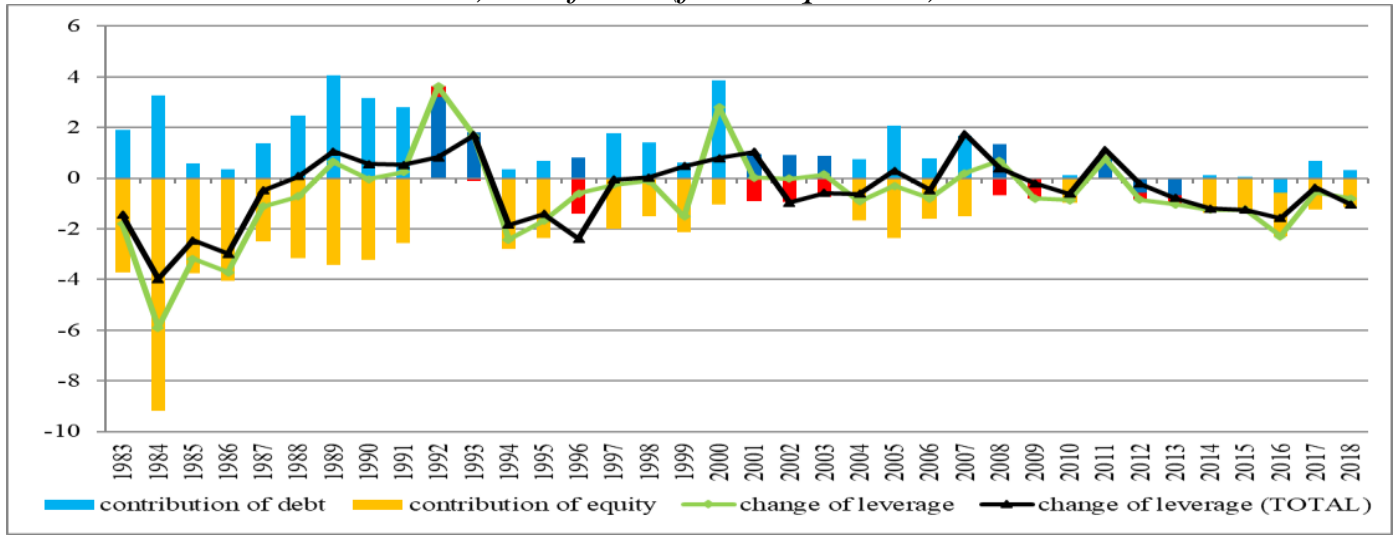

Figure A11 - Change of leverage and contribution of debt and equity - Firms with EBITDA<0

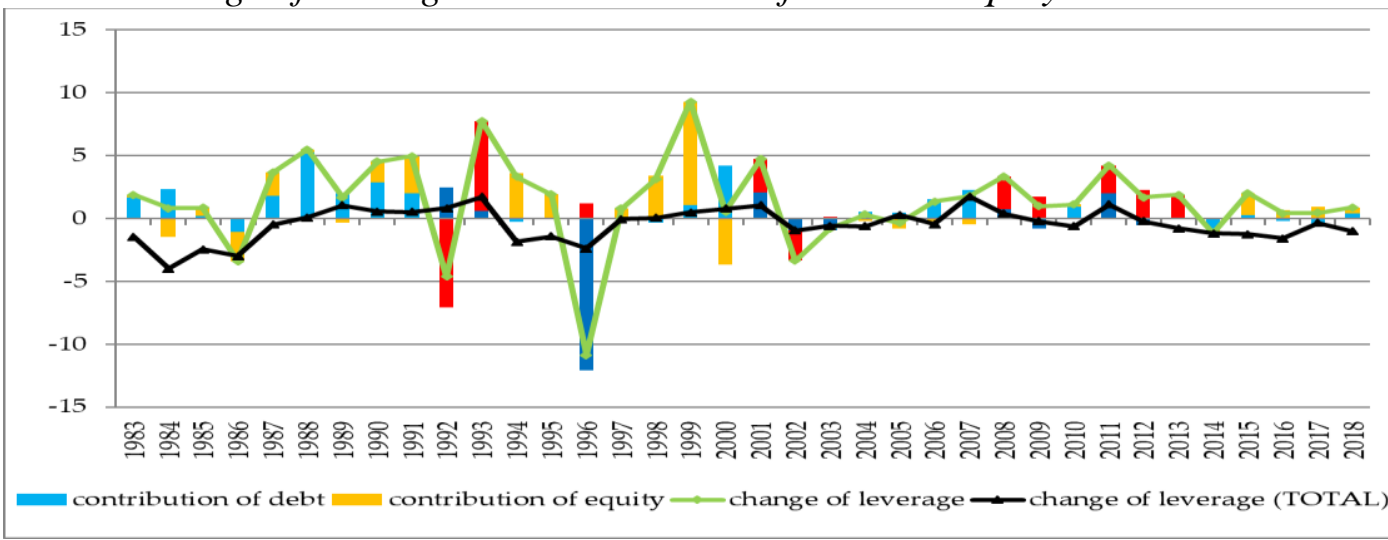


Figure A12 - Change of leverage and contribution of debt and equity a) Sound firms

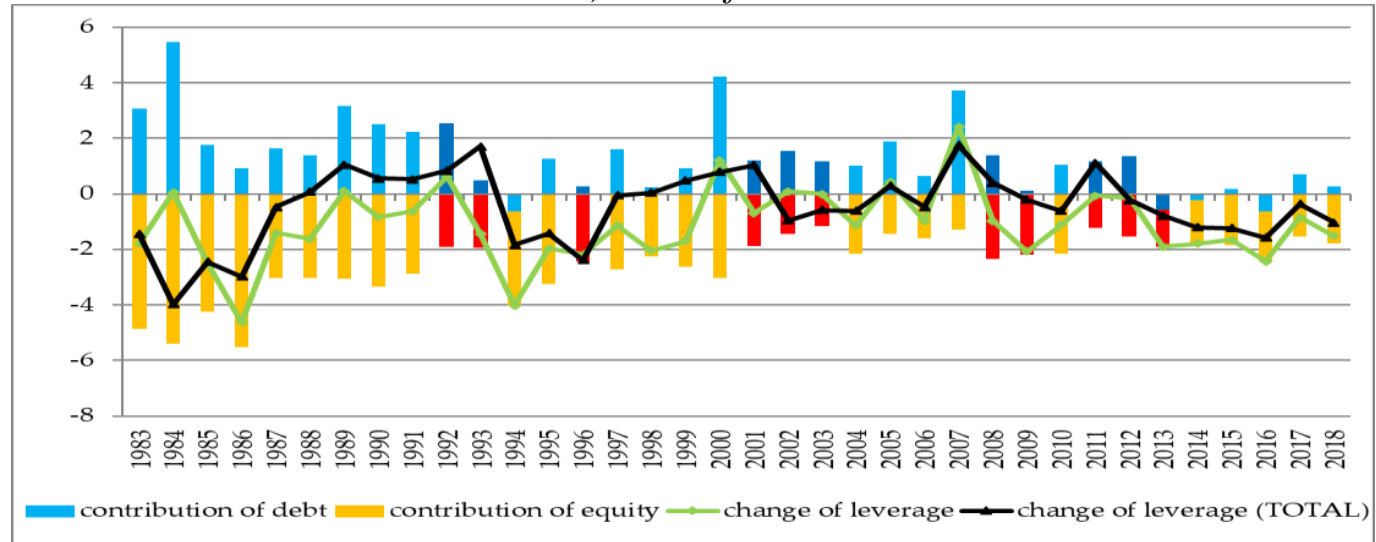

b) Vulnerable firms

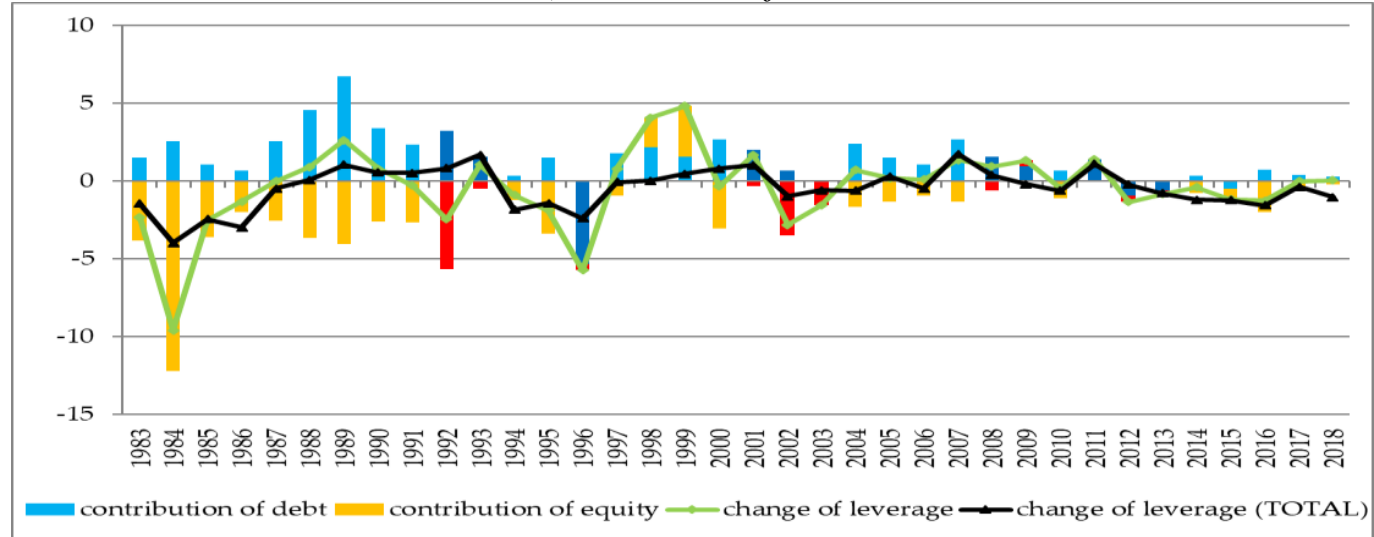

c) Risky firms

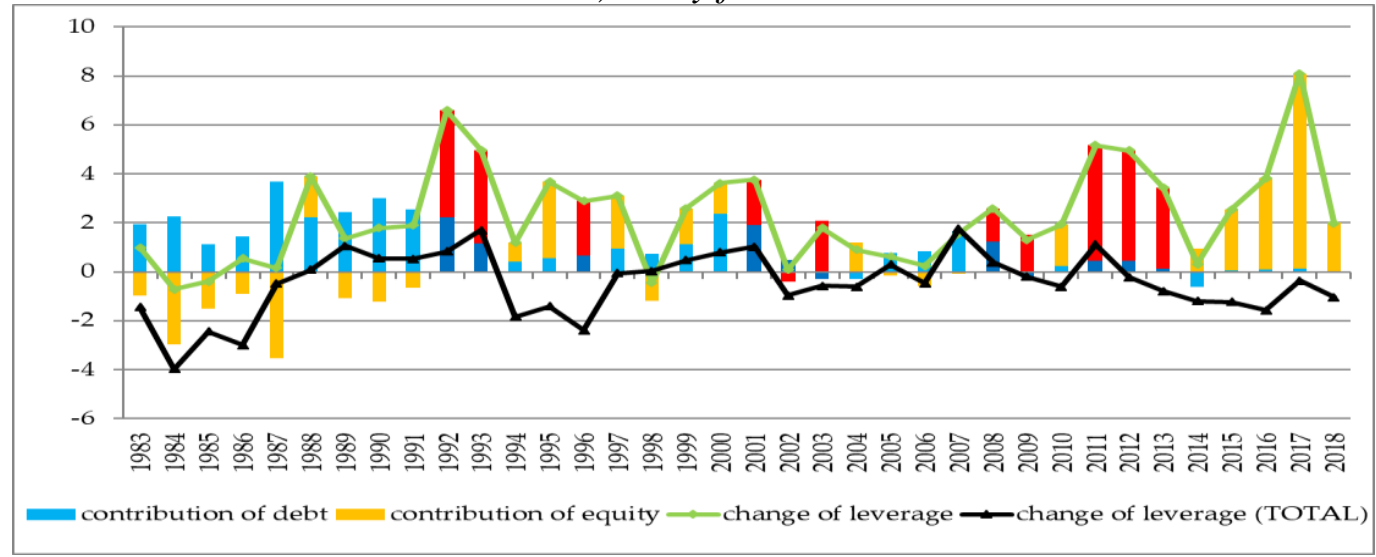


Figure A13 - Change of leverage and contribution of debt and equity

a) Firms with short term debt only

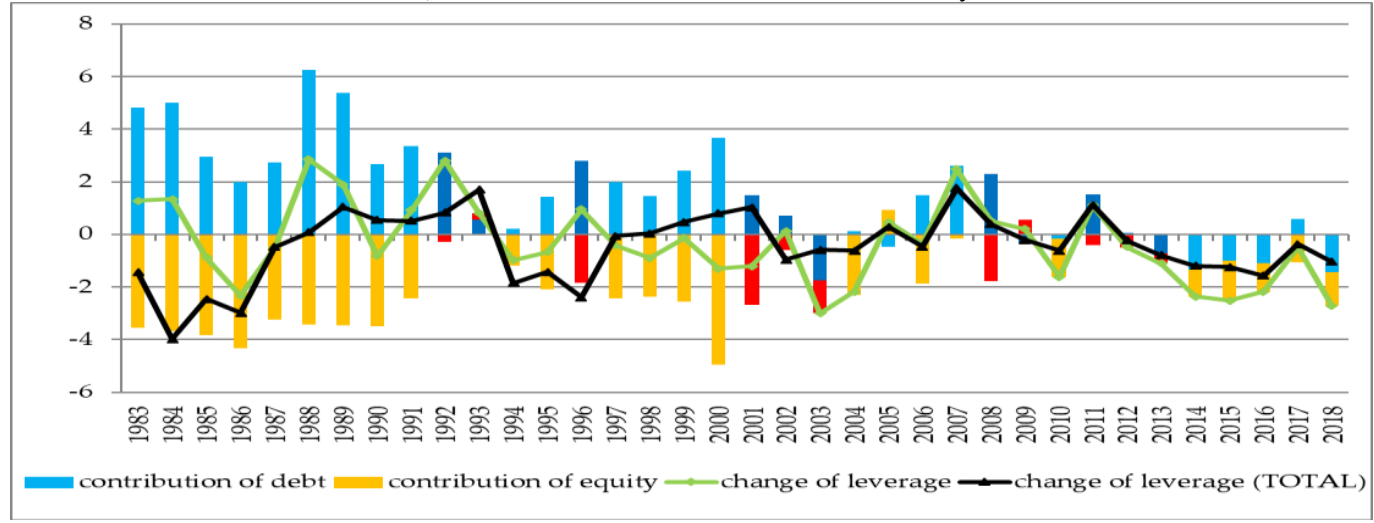

b) Firms with bank debt only

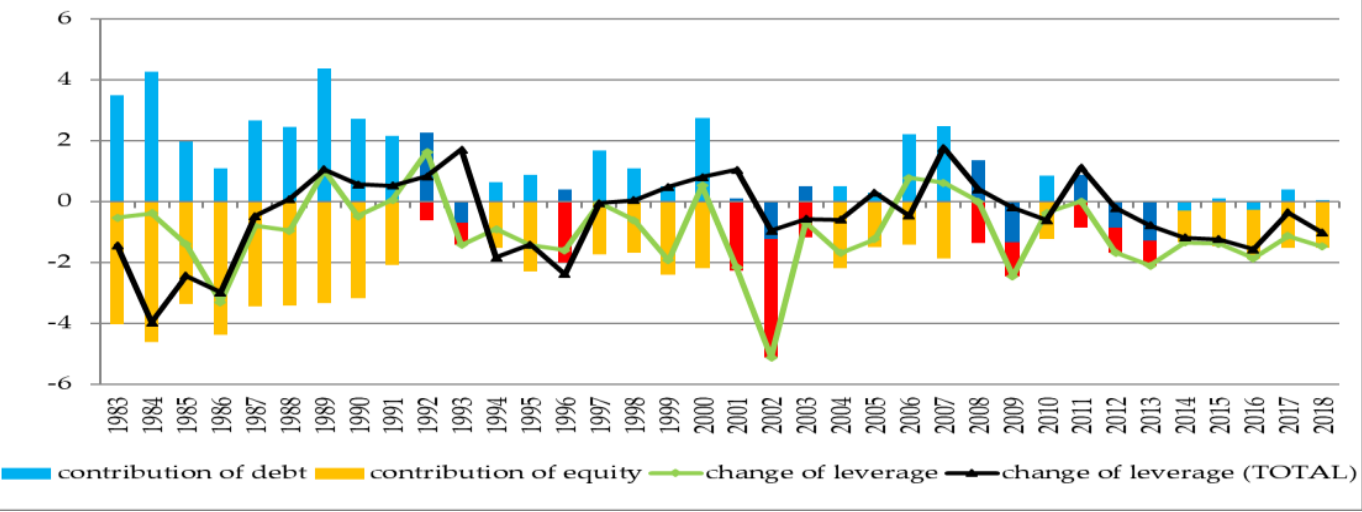

Appendix A5 - Regressions: descriptive statistics, robustness checks, extensions

Figure A14 shows the main statistics (means and quartiles) of the two components of leverage during the time span under analysis. The contribution of debt to leverage is on average positive and decreasing over time (Figure A14.a); in particular, the third quartile goes down more, so that the distribution becomes nearly symmetric since the 2000s. The contribution of equity to leverage is mostly negative (due to losses it is however positive in 1992-93 and 2012-13) and the distribution is very asymmetric: the changes are close to zero for around 75 per cent of firms and the negative contribution to leverage is substantial for the first quartile, especially in the 80s (Figure A14.b).

Figure A14 - Changes over time: mean and distribution by year (percentage points)

a) contribution of debt

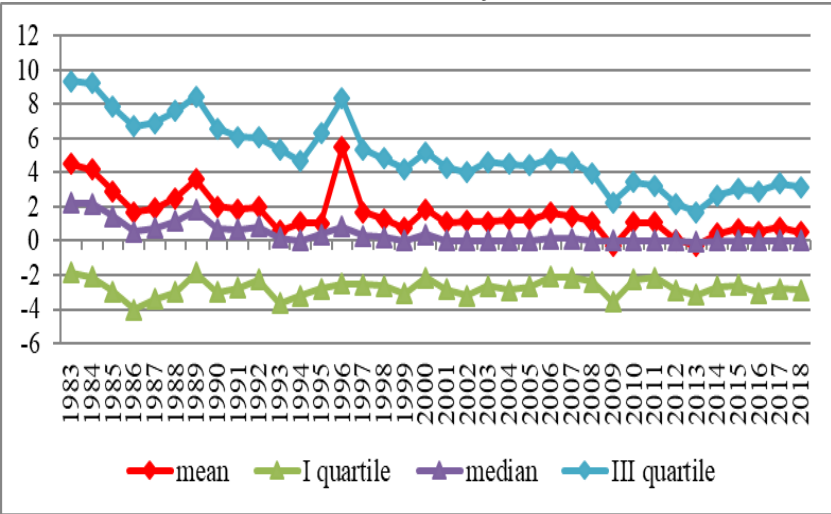

b) contribution of equity

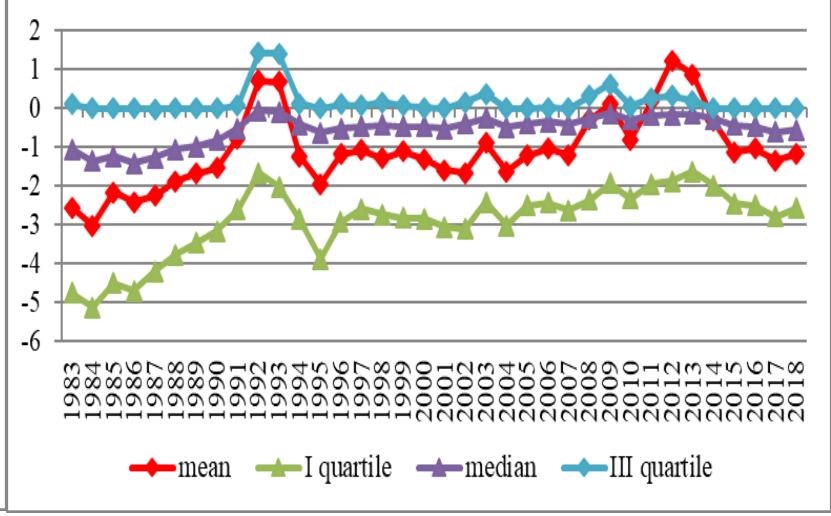


Table A3 shows a different identification of the business cycles. In regressions (1-3), the constant terms implicitly measure the average of the variables of interest (changes of leverage and the contributions of debt and equity) in both years preceding and following slumps. In principle the relations under analysis may differ, because the previous could represent a slowdown before the peak and the latter a recovery after the through. In order to evaluate the robustness of the dummy "BUST", I consider a specification based upon three different periods, by dividing the booms (when BUST=0) into years that are closer to a through ("After_BUST=1") and those that are closer to a peak ("Before_BUST=1").

Table A3 - Alternative definitions of business cycles

\begin{tabular}{|c|c|c|c|c|c|c|c|c|c|c|c|c|c|c|c|c|c|c|c|c|c|c|c|c|c|c|c|c|c|c|c|c|c|c|c|c|}
\hline & 1983 & & & & 1987 & & & 1990 & 1991 & 1992 & 1993 & 1994 & 1995 & 1996 & 1997 & 1998 & 1999 & 2000 & 2001 & 2002 & 2003 & 2004 & 2005 & 2006 & 2007 & 2008 & 2009 & 2010 & 2011 & 12012 & 2013 & 32014 & 2015 & 52016 & 62017 & 2018 \\
\hline BUST & 0 & 0 & 0 & 0 & 0 & 0 & 0 & 0 & 0 & 1 & 1 & 0 & 0 & 1 & 0 & 0 & 0 & 0 & 1 & 1 & 1 & 0 & 0 & 0 & 0 & 1 & 1 & 0 & 1 & 1 & 1 & 0 & 0 & 0 & 0 & 0 \\
\hline BUST $_{+1 \mathrm{Y}}$ & 1 & 0 & 0 & 0 & 0 & 0 & 0 & 0 & 0 & 0 & 1 & 1 & 0 & 0 & 1 & 0 & 0 & 0 & 0 & 1 & 1 & 1 & 0 & 0 & 0 & 0 & 1 & 1 & 0 & 1 & 1 & 1 & 0 & 0 & 0 & 0 \\
\hline After BUST & 1 & 1 & 1 & 1 & 0 & 0 & 0 & 0 & 0 & 0 & 0 & 1 & 0 & 0 & 1 & 1 & 0 & 0 & 0 & 0 & 0 & 1 & 1 & 0 & 0 & 0 & 0 & 1 & 0 & 0 & 0 & 1 & 1 & 1 & 0 & 0 \\
\hline Before BUST & 0 & 0 & 0 & 0 & 1 & 1 & 1 & 1 & 1 & 0 & 0 & 0 & 1 & 0 & 0 & 0 & 1 & 1 & 0 & 0 & 0 & 0 & 0 & 1 & 1 & 0 & 0 & 0 & 0 & 0 & 0 & 0 & 0 & 0 & 1 & 1 \\
\hline
\end{tabular}

The three robustness regressions include the dummy "After_BUST", which differs from the "BUST $+1 Y$ " in regressions (4-6) as it: i) explicitly considers years following a through; ii) includes a longer time span. They are specified as follows:

$$
\begin{aligned}
& \text { (1rob) } \mathrm{DLEV}_{\mathrm{it}}=\mathrm{a}_{\mathrm{i} 7}+\beta_{7} \mathrm{BUST}+\gamma_{7} \text { After_BUST }+\mathrm{e}_{7 \mathrm{it}} \\
& \text { (2rob) } \mathrm{DF}_{\mathrm{it}}=\mathrm{a}_{\mathrm{i} 8}+\beta_{8} \mathrm{BUST}+\gamma_{8} \text { After_BUST }+\mathrm{e}_{8 \mathrm{it}} \\
& \text { (3rob) } \mathrm{EQ}_{\mathrm{it}}=\mathrm{a}_{\mathrm{i} 9}+\beta_{9} \mathrm{BUST}+\gamma_{9} \text { After_BUST }+\mathrm{e}_{9 \mathrm{it}}
\end{aligned}
$$

Table A4 compares the baseline specifications (columns 1-6) and the robustness checks (columns 1rob-3rob), where the results obtained when the years out of busts (i.e. Constant in regressions 1-3),

\begin{tabular}{|c|c|c|c|c|c|c|c|c|c|}
\hline & (1) & (2) & (3) & (4) & (5) & (6) & (1rob) & (2rob) & (3rob) \\
\hline VARIABLES & DLEV & DF & EQ & DLEV & DF & EQ & DLEV & DF & EQ \\
\hline BUST & $\begin{array}{c}0.765^{* * *} \\
(0.0301)\end{array}$ & $\begin{array}{c}-0.399 * * * \\
(0.0255)\end{array}$ & $\begin{array}{l}1.196 * * * \\
(0.0180)\end{array}$ & & & & $\begin{array}{l}0.779 * * * \\
(0.0345)\end{array}$ & $\begin{array}{c}-0.461 * * * \\
(0.0299)\end{array}$ & $\begin{array}{c}1.280 * * * \\
(0.0199)\end{array}$ \\
\hline $\mathrm{BUST}_{+1 \mathrm{Y}}$ & & & & $\begin{array}{c}-0.115^{* * *} \\
(0.0293)\end{array}$ & $\begin{array}{c}-0.928 * * * \\
(0.0249)\end{array}$ & $\begin{array}{l}0.861 * * * \\
(0.0174)\end{array}$ & & & \\
\hline After_BUST & & & & & & & $\begin{array}{c}0.0256 \\
(0.0320)\end{array}$ & $\begin{array}{c}-0.114 * * * \\
(0.0287)\end{array}$ & $\begin{array}{c}0.152^{* * *} \\
(0.0169)\end{array}$ \\
\hline Constant & $\begin{array}{c}0.289 * * * \\
(0.0107)\end{array}$ & $\begin{array}{l}1.431^{* * *} \\
(0.00904)\end{array}$ & $\begin{array}{c}-1.321 * * * \\
(0.00637)\end{array}$ & $\begin{array}{l}0.602 * * * \\
(0.0105)\end{array}$ & $\begin{array}{c}1.624^{* * *} \\
(0.00896)\end{array}$ & $\begin{array}{c}-1.207^{* * *} \\
(0.00624)\end{array}$ & $\begin{array}{l}0.276 * * * \\
(0.0200)\end{array}$ & $\begin{array}{l}1.492 * * * \\
(0.0178)\end{array}$ & $\begin{array}{c}-1.402 * * * \\
(0.0109)\end{array}$ \\
\hline Observations & 1665896 & 1665896 & 1665896 & 1665896 & 1665896 & 1665896 & 1665896 & 1665896 & 1665896 \\
\hline R-squared & 0.000 & 0.000 & 0.003 & 0.000 & 0.001 & 0.002 & 0.000 & 0.000 & 0.004 \\
\hline Number of firms & 165813 & 165813 & 165813 & 165813 & 165813 & 165813 & 165813 & 165813 & 165813 \\
\hline
\end{tabular}
are divided into periods preceding a bust (Constant) and following it (After_BUST).

Table A4 - Business cycles and leverage, debt and equity: baseline (1-6) and robustness (1rob-3rob) 
The values of the dummies BUST are similar in columns (1-3) and (1 rob-3rob), confirming that leverage increases more during slumps. Also the values of Constant in regressions (1-3) are very close to the corresponding estimates in regressions (1rob-3rob): therefore, the coefficients in the baseline estimations basically proxy the average changes during the expansionary years preceding a bust, which are explicitly identified in the robustness tests. This evidence is confirmed by the fact that, during recoveries, leverage goes up with respect to years preceding a slump only marginally but the difference is not statistically significant (dummy After_BUST compared with Constant in column 1rob).

Overall, the findings of the robustness estimations are reassuring because they imply that the simpler and more straightforward approach (regressions 1-3) is able to disentangle the different behaviour of leverage, debt and equity during the booms and busts of the business cycle.

Figure A15 shows the results by sector of economic activity and confirms the main findings in case of manufacturing and services: leverage increases during busts mainly due to equity contribution and decreases with a lag due to debt dynamics. Instead, leverage increases also with a lag in the construction sector due to a more persistent positive contribution of equity.

Figure A15 - Estimates of change of leverage and of its components (percentage points) by sector of economic activity

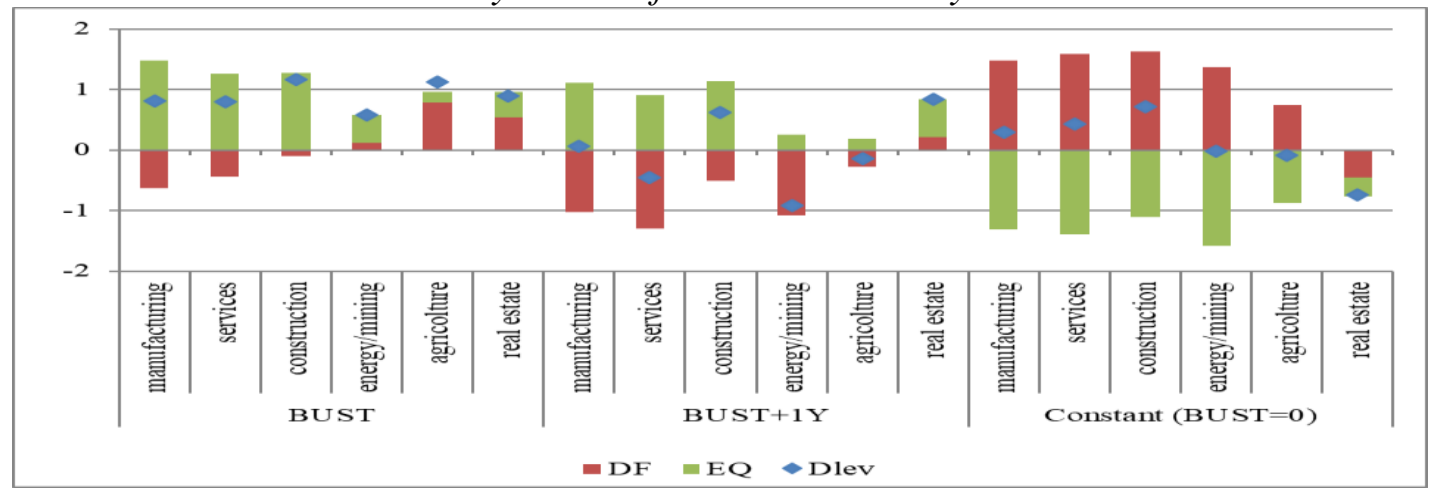

Figure A16 shows leverage and net leverage (excluding liquidity) and their difference; it is clear that after three busts the deleveraging process coupled with increasing liquidity.

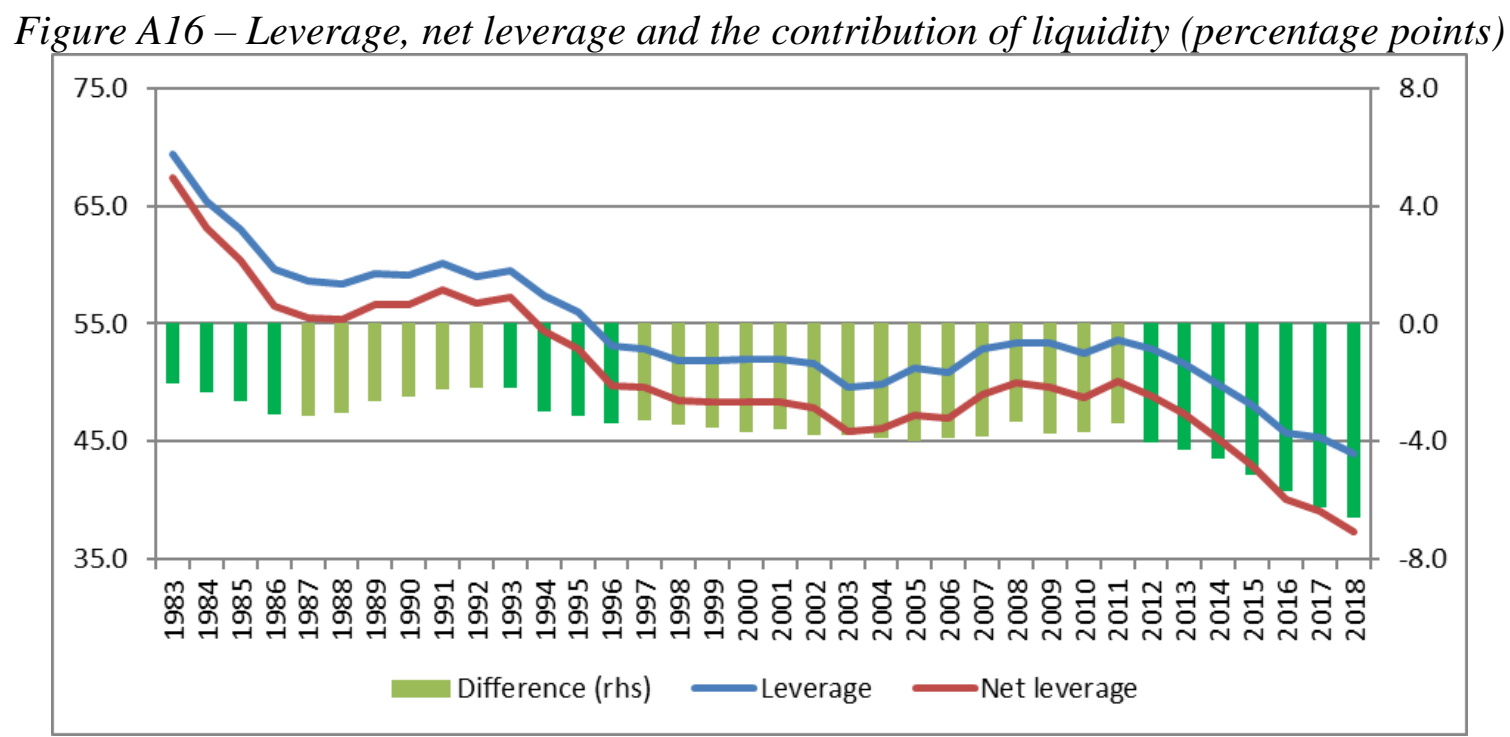

